\title{
Progress in satellite remote sensing for studying physical processes at the ocean surface and its borders with the atmosphere and sea ice
}

\author{
Shutler Jamie D. ${ }^{1,{ }^{*}}$, Quartly Graham D. ${ }^{2}$, Donlon Craig J. ${ }^{3}$, Sathyendranath Shubha ${ }^{2}$, Platt Trevor ${ }^{2}$, \\ Chapron Bertrand ${ }^{4}$, Johannessen Johnny A. ${ }^{5}$, Girard-Ardhuin Fanny ${ }^{4}$, Nightingale Philip D. ${ }^{2}$, \\ Woolf David K. ${ }^{6}$, Hoyer Jacob L. ${ }^{7}$
}

${ }^{1}$ Univ Exeter, Exeter EX4 4QJ, Devon, England.

2 Plymouth Marine Lab, Plymouth, Devon, England.

${ }^{3}$ European Space Agcy, F-75738 Paris 15, France.

${ }^{4}$ Inst Francais Rech Exploitat Mer IFREMER, Nancy, France.

${ }^{5}$ NERSC, Bergen, Norway.

${ }^{6}$ Heriot Watt Univ, Edinburgh EH14 4AS, Midlothian, Scotland.

${ }^{7}$ Danish Meteorol Inst, Odense, Denmark.

* Corresponding author : Jamie D. Shutler, email address : j.d.shutler@exeter.ac.uk

\begin{abstract}
:
Physical oceanography is the study of physical conditions, processes and variables within the ocean, including temperature-salinity distributions, mixing of the water column, waves, tides, currents and airsea interaction processes. Here we provide a critical review of how satellite sensors are being used to study physical oceanography processes at the ocean surface and its borders with the atmosphere and sea ice. The paper begins by describing the main sensor types that are used to observe the oceans (visible, thermal infrared and microwave) and the specific observations that each of these sensor types can provide. We then present a critical review of how these sensors and observations are being used to study: (i) ocean surface currents, (ii) storm surges, (iii) sea ice, (iv) atmosphere-ocean gas exchange and (v) surface heat fluxes via phytoplankton. Exciting advances include the use of multiple sensors in synergy to observe temporally varying Arctic sea ice volume, atmosphere-ocean gas fluxes, and the potential for four-dimensional water circulation observations. For each of these applications we explain their relevance to society, review recent advances and capability, and provide a forward look at future prospects and opportunities. We then more generally discuss future opportunities for oceanographyfocused remote sensing, which includes the unique European Union Copernicus programme, the potential of the International Space Station and commercial miniature satellites. The increasing availability of global satellite remote-sensing observations means that we are now entering an exciting period for oceanography. The easy access to these high quality data and the continued development of novel platforms is likely to drive further advances in remote sensing of the ocean and atmospheric systems.
\end{abstract}


Keywords: Atmosphere-ocean interface, sea ice, remote sensing, surface currents, storm surge, surface heat fluxes, atmosphere-ocean gas fluxes, oceanography

\section{Introduction}

The oceans provide a plethora of services to society from climate regulation, the provision of food and minerals, and the transport of goods. For instance, proteins derived from fish, crustaceans and molluscs account for between $14 \%$ and $17 \%$ of the animal protein intake of the worlds human population (WHO, 2014) and $90 \%$ of the worlds trade is carried across the oceans (IAEA, 2014). Thus, studying and monitoring the health of the oceans and their physical, chemical and biological components is key for predicting future climate and maintaining life on Earth.

Physical oceanography is the study of the physical conditions, processes and variables within the ocean. In this context the word 'physical' refers to the physical parameters of structure and motion. This includes a large range of oceanic properties and characteristics including temperature-salinity distribution, mixing, waves, tides, surface and sub-surface currents, and the exchanges (fluxes) of heat, momentum and gas between the ocean and the atmosphere.

Space-based remote-sensing observations have an important role to play in oceanography research and monitoring through providing quasi-synoptic and reproducible data for investigating processes on global scales (Land et al., 2015). The present period (2016) is an exciting period of satellite remotesensing with sustained investment in long-term monitoring programmes scientifically driven from international organisations, directives, space agencies and commercial enterprises. Satellites with a large range of sensors are now in orbit and these new observations along with historical datasets are in the most part freely and routinely 
available to a broad range of users over the Internet (figure 1). Individual sensors used for remote-sensing may exploit visible light, infra-red or microwave radiation - the common theme for all of these sensors is that the electromagnetic waves that they observe must interact with the ocean, thus providing information on some property of the ocean surface or water column, whilst not being completely absorbed or scattered by the atmosphere or ocean.

This critical review and forward look begins by providing an overview of the existing remotesensing technologies and the ocean properties that they observe, with a particular emphasis on their use for studying physical processes at the ocean surface and its borders with the atmosphere and sea-ice. These technologies are able to make observations at different spatial scales of processes occurring in the oceans, from microscale $(<10 \mathrm{~km})$, through mesoscale $(10-1000 \mathrm{~km})$ to synoptic scale $(>1000 \mathrm{~km})$ and this paper presents examples of all of these. We then focus on five areas where considerable research effort has been focused over the last 5 years with exciting developments for ocean and atmosphere science. These areas are surface currents (section 2), storm surges (section 3), sea-ice (section 4), atmosphere-ocean gas fluxes (section 5) and surface heat fluxes (section 6). The research in all of these areas has exploited multiple sensors and in many cases has also begun to exploit multi-sensor synergy approaches. Each of the sections in this paper begins with an overview of the oceanography theory, briefly highlights the societal relevance of the application, and then describes recent developments and advances. The paper then concludes in Section 7 with a forward look and highlights future research and development opportunities, including the European Union Copernicus programme and commercial satellite activities.

[Figure 1 here]

\section{Visible spectrum sensors}

Visible spectrum remote-sensing is commonly used for showing real-time environmental conditions in the media, such as over-head views of hurricanes and weather systems. Such images illustrate the challenges in visible spectrum remote-sensing: clouds, sea mist, or aerosol contamination such as desert dust can all block the view of the (often more subtler) colour changes within the surface ocean. These "ocean colour" sensors thus operate at a number of narrow spectral bands, each of which covers specific wavelength regions of the visible spectrum 
(for example 8 spectral bands for the Sea Viewing Wide Field of View Sensor, SeaWiFS and 15 for Medium Resolution Imaging Spectrometer, MERIS) that permit a careful screening for intervening haze, allow the calculation and removal of effects of the atmosphere, and relate the spectra of water-leaving radiances to surface properties. Although the majority of ocean colour data are used to study ocean biology such as surface chlorophyll-a concentrations (which is not covered in this review, but a plethora of useful reviews are contained within the series of books available from the International Ocean Colour Co-ordinating Group, IOCCG, http://www.ioccg.org), information on some physical properties can also be derived. This is because the biological signal in the ocean colour data can be used as a proxy for the structure and/or motion of the water (as covered in sections 2 and 5). For instance areas of locally high chlorophyll concentration may indicate regions of upwelling (upwelled water supplies nutrientrich water for the biology) or vertical lifting of near-surface layers caused by internal waves e.g. (Muacho et al., 2013). The ocean colour signal can also act as an indicator of a particular water mass, with boundaries between optically different water bodies being indicators of fronts between regions of different temperature and salinity properties e.g. (Fratantoni and Glickson, 2002). Sequential ocean colour data can also be used to infer the velocity of features through maximum cross correlation of high-resolution images (Yang et al., 2014) as described in section 2 of this paper.

\section{Thermal infra-red sensors}

Thermal infra-red sensors observe the thermal radiation that is emitted from the skin of the sea surface, where the skin is considered to be top millimetre or so of the water. As is the case for visible spectrum sensors, clouds and haze may obscure the sea surface or affect the signal that reaches the satellite sensor. Thus thermal infra-red radiometers operate at multiple channels (wavelengths) so that an atmospheric correction algorithm can be used to correct for atmospheric attenuation, allowing the sea surface temperature (SST) to be determined e.g. (McClain et al., 1985). As water is a strong emitter of thermal infra-red radiation, the received signal corresponds to a skin depth of a few microns. This sea surface skin temperature controls heat and gas exchange with the atmosphere, and, provided there is some turbulent mixing by wind and waves is often close to the temperature a few metres below the surface, i.e. that recorded by ships and floats. As well as providing temperature observations and contributing to 
calculation of heat and gas fluxes (see sections 5 and 6), thermal infra-red sensor data can also be used to provide estimates of ocean currents through the apparent migration of features, using techniques such as maximum cross-correlation (section 2).

[Figure 2 here]

\section{Passive microwave sensors}

In the frequency range $1-200 \mathrm{GHz}$ range (wavelengths of $30 \mathrm{~cm}$ to $0.15 \mathrm{~cm}$ ) the surface emissivity of the ocean is affected by properties such as temperature, salinity and roughness. Microwave sensors operating at these frequencies are often stated to have an "all weather capability". This is not completely true, as although microwave signals are unperturbed by clouds (offering a great advantage with respect to visible and thermal infra-red sensors), significant atmospheric liquid (rain) will prevent the recovery of accurate information on the sea surface. Emissions at $85 \mathrm{GHz}$ act as a good discriminator for the presence of sea-ice (section 4.0) and enable observations at a spatial resolution of $\sim 5 \mathrm{~km}$ (Comiso et al., 2003). Passive microwave sensors typically have channels at $37 \mathrm{GHz}$ and $22 \mathrm{GHz}$, which are used for the detection and quantification of rain and water vapour respectively. In the absence of rain, wind is an important influence through its effect on sea surface roughness; sensors typically use combinations involving either $37 \mathrm{GHz}$ or $11 \mathrm{GHz}$ to infer wind speed (Wentz, 1997). We provide case studies of its use in sections in sections 2 and 5 . Microwave frequencies in the range 6.5$11 \mathrm{GHz}$ have a good sensitivity to SST although the contribution of wind speed needs to be estimated and removed to determine accurate estimates of SST. The footprint size is typically $\sim 40-60 \mathrm{~km}$, and hence not suitable for recording filamentary (microscale) structures or any features near the coast (as the land-sea adjacency effect contaminates the signal). Microwave frequencies of about $1.4 \mathrm{GHz}$ can be used to observe sea surface salinity (Gabarró et al., 2004). However, both temperature and wind-roughening of the surface cause greater variability at this frequency, so both wind speed and SST need to be recorded at the same time, or else a reliable model estimate is required to allow the surface salinity to be determined. Only two satellite sensors have been launched to specifically study ocean salinity. These are the Surface Moisture Ocean Salinity, SMOS sensor and the NASA sensor Aquarius and they are already providing new insights beyond their original mission focus e.g. Land et al. (2015); Reul et al. 
(2012). Sections 2, 4 and 5 all include aspects of the use of salinity observations and/or the use of SMOS.

\section{Active microwave sensors - scatterometers and synthetic aperture radar}

Active microwave sensors emit a microwave signal and record its reflection from the ocean surface. The surface observed is thus a measure of the ocean's directional scattering rather than its emissivity. The strength of reflected signal depends upon the frequency, the polarization and the viewing angle, as well as the roughness of the sea surface (due to the action of wind and waves). Active scatterometer and synthetic aperture radar (SAR) sensors can provide observations of both wind speed and direction which is vital for meteorological studies, and is important in oceanography to determine the Ekman ocean current it generates. The spatial resolution of scatterometer data is currently quite coarse $(25-50 \mathrm{~km})$ because of the need for averaging in order to reduce the effect of fading noise. In contrast the spatial resolution of SAR data is typically of the order of a few metres. This combined with the large swath widths (of up to $450 \mathrm{~km}$ ) enables SARs to image wave and wind fields, often enabling atmospheric boundary rolls, and swell wavelength and direction to be recovered e.g. see Robinson (2010). Horizontal surface current gradients also affect short scale waves, which means that SAR data can be used to study tidal flows over shallow bathymetry (Alpers and Hennings, 1984). The same physical mechanisms help SAR data to reveal internal waves (Kudryavtsev et al., 2005; Kudryavtsev et al., 2014; da Silva et al., 2009) which can lead to intense upper-ocean mixing (Kozlov et al., 2012). Anomalous SAR Doppler signals can also be used to help map the line-ofsight surface current component (see section 2). All of the above scatterometer and SAR active sensor techniques are used within the work described in sections 2, 4 and 5.

\section{Active microwave sensors - Radar altimeters}

Radar altimeters are generally active microwave instruments that operate only in the nadir direction. Microwave pulses are emitted by the altimeter, these then reflect off the sea surface and the time needed for the signal to return to sensor enables the height of the ocean to be calculated. The careful processing and validation of altimetric data has been key to the study of global mean sea level rise over the past two decades, revealing not only a general rise in the global average of $3.3 \mathrm{~mm} \mathrm{yr}^{-1}$, but significant regional variation (AVISO, 2015). Gradients in sea surface height (SSH) are directly related to currents (assuming the flow has reached 
geostrophic equilibrium, see section 2.1). Interpretation of altimetry data in the coastal zone used to be problematic, but now reliable sea level data are available within a few kilometres of the coast due to improved editing and atmospheric corrections (Bouffard et al., 2008), reduced errors in tide models (Stammer et al., 2014) and more robust techniques for retrieving the sea level signal from an altimeter's radar echoes (Passaro et al., 2014). This use of altimeter data is discussed in section 3.0. As with other active microwave instruments the strength of the reflected signal is a measure of sea surface roughness, and thus can be associated with the effect of wind speed on the water surface. Most altimeters have operated at $\sim 13.6 \mathrm{GHz}$, so a well-validated relationship has been developed between signal strength and wind speed (Zieger et al., 2009), although since rain also affects the return signal (Guymer et al., 1995) such data need to be screened and removed to avoid erroneous data. Further analysis of the shape of the reflected altimeter echo allows the determination and study of the significant wave height e.g. (Young et al., 2011). The use of altimeter sea surface roughness, wind speed and significant wave height are covered in sections $2,3,4$ and 5.

\section{Overview}

The many instruments currently in orbit about the Earth each provide many different observations of the physical properties of the ocean surface. More detailed explanations of the sensor characteristics and uses can be found in remote-sensing reference texts, in particular (Robinson, 2010) provides a comprehensive overview. Next we critically review how these observations are being exploited to investigate ocean surface currents, storm surges, sea ice, atmosphere-ocean gas exchange and surface heat fluxes.

\section{Ocean surface currents}

Surface current measurements over a broad range of spatial and temporal scales are important for a wide variety of applications including industry (e.g. oil drilling, shipping), provision of food (e.g. fishing), recreation (e.g. sailing), safety (e.g. search and rescue) and environmental research (e.g. climate modelling). For example, oil, fuel and other pollutants on the ocean surface travel with the surface currents, and as such, protection management and clean up operations often exploit real-time surface current information. Furthermore, the transport of fish 
larvae, the movement of ice, and the exchange of gases between the ocean and atmosphere are all influenced by ocean currents.

Oceanic currents are driven by several factors. Firstly, tides create tidal currents in the open ocean, near the shore, and in bays and estuaries along the coast. They are the only type of currents that vary in a regular pattern. In some coastal regions the tidal currents can reach up to $5 \mathrm{~ms}^{-1}$ and these are the strongest currents encountered in the ocean. Secondly, near surface winds drive currents (usually of a magnitude up to $0.10-0.30 \mathrm{~ms}^{-1}$ ) that are at or near the ocean's surface and can occur over localised spatial extents (order of $10 \mathrm{~km}$ ) in coastal regions or over larger regional extents (order of $100 \mathrm{~km}$ ) in the open ocean. Thirdly, currents are driven by thermohaline circulation, caused by the density differences in the ocean due to the temperature (thermo) and salinity (haline) fields and their variations in different parts of the global oceans. Thermohaline circulation driven currents occur both in deep and shallow waters and move much slower (of the order $0.01 \mathrm{~m} \mathrm{~s}^{-1}$ ) than tidal or surface currents. A fourth factor that can drive currents are differences in water pressure (caused by density gradients); a process termed geostrophy e.g. see (Stewart, 2012). A geostrophic current will form at 90 degrees to water pressure isobars, and due to the influence of the rotating Earth (Coriolis effect), the direction of flow will be right (left) of the pressure gradients in the northern (southern) hemisphere. This last concept allows oceanographers to infer currents from SSH data.

Except for the Antarctic Circumpolar Current, ocean basins generally have a non-symmetric surface current, in that the eastern equator-ward-flowing branch is broad and diffuse, whereas the western poleward flowing branch is very narrow. These western boundary currents (e.g. the Gulf Stream, the Kuroshio, the Agulhas Current) are a consequence of basic geophysical fluid dynamics, notably their western intensification, and are accompanied by poleward transport of warm and saline water from the tropics e.g. see (Stewart, 2012).

A combination of different satellite remote-sensing datasets and techniques can provide an improved and advanced understanding of the upper ocean dynamics. The following sections describe and review these approaches.

\section{Currents from radar altimetry}

Measurements of the SSH have been routinely obtained from satellite altimeter missions for the 
last 20 years. Today the annual mean $\mathrm{SSH}$ derived from altimetry is known with millimetre accuracy e.g. (Cazenave et al., 2009) in the open ocean. As long-term changes in ocean surface currents result in a geostrophic balance, the SSH gradients derived from altimetry are used to investigate temporal and spatial changes in the large basin-scale circulation patterns and frontal boundaries associated with geostrophically balanced mesoscale eddies, and their influence on the upper ocean dynamics.

A spatial gradient in SSH can only be maintained if balanced by the Coriolis force. This means that the gradient in SSH provides information on the current perpendicular to it. Thus a major current such as the Gulf Stream is marked by a change in $\mathrm{SSH}$ of $\sim 1 \mathrm{~m}$ between the two sides of the flow. Eddies (rotating bodies of water with typical diameters between 50-500 km depending on the Rossby radius of deformation) are indicated by closed contours of SSH and significant vorticity, enabling their migration to be tracked over months to years using altimetry for example using sensors such as Topex/Posidon and the European Remote Sensing (ERS) satellites (Chelton et al., 2007)

From the satellite sensor detected along-track gradients of the SSH anomalies the cross-track geostrophic velocity is calculated at a spatial resolution of about $10 \mathrm{~km}$ (figure 3). This provides an estimate of the time-varying part of the surface velocity field, relative to a mean circulation, except in a zonal band along the equator where the Coriolis parameter is zero and the geostrophic assumption does not apply. This time-variable part of the surface current field can be used to study and monitor changes in the location and strength of current fronts and eddies. Such a time sequence of altimeter-derived SSH anomalies over several years yields valuable information about the relationships between eddies on different spatial scales and their dependence on the strength of surface currents as they vary over the seasons and years. By merging such altimeter mission data, the mean and eddy kinetic flow have been characterised and investigated for the Gulf Stream, the Kuroshio, the Malvinas and the Agulhas Currents (Le Traon et al., 1998; Ducet et al., 2000; Okkonen et al., 2001; Fu, 2007) which has revolutionised understanding of the temporal and spatial variability of these systems.

It is not possible to optimise the sampling of any single altimeter satellite mission to observe all oceanic processes and regions at all spatial scales of interest. Since 1992 there have been at least two and sometimes as many as four altimeters in orbit at the same time. When the orbits 
of these instruments are harmonised the along-track data from each of them can be interpolated to a common grid to reduce mesoscale spatial errors (Le Traon et al., 1998). For the combination of data from Topex/Poseidon and the ERS satellite, for example, the sea level mean mesoscale mapping error was reduced by a factor of 4 and the standard deviation reduced by a factor of 5 (Le Traon and Dibarboure, 1999) compared with those for Topex/Poseidon alone.

[Figure 3 here]

\section{Currents from SST, SAR and ocean colour using feature tracking}

Feature tracking of distinct frontal structures can be used to retrieve the absolute or mean current from multi-temporal SST, SAR and ocean colour data. These retrievals can be used to complement the analysis of signatures of surface current gradients. This is because the information on mean currents can be valuable for the generation of a first-guess current field for further iterative optimization across the frontal current gradient. Hence, as long as two or more scenes of the same surface current feature are available (with a time lag that is short compared to the de-correlation time of the structure), then features that are moving with the background (underlying) surface current can be tracked. In turn, this means that the surface current vectors can then be determined from the differences in location of these features between the different image scenes. The feature tracking algorithm itself can be an extended feature detection algorithm, or an algorithm analysing the cross correlation function of the two images for individual sub-areas. For a correct calibration of the results, accurate georectification and collocation of the images is needed (e.g. misaligned image pairs will result in anonymous motion detection).

The Maximum Cross Correlation (MCC) method e.g. (Emery et al., 1986; de Souza et al., 2006; Crocker et al., 2007; Yang et al., 2014) is an automated procedure that calculates the displacement of small regions of patterns from one image to another. This procedure, mostly applied to infrared and ocean colour data, cross-correlates a template sub-window in an initial image with all possible sub-windows of the same size that fall within the search window of a second image. The location of the sub-window in the second image that produces the highest cross-correlation with the sub-window in the first image indicates the most likely displacement 
(movement) of that feature. The velocity vector is then calculated by dividing the displacement vector by the time separation between the two images (figure $2 b$ ).

\section{Current retrievals from SAR based range Doppler}

Estimates of a geophysical Doppler shift can be obtained by subtracting a predicted Doppler shift, based on precise knowledge of the satellite orbit and attitude, from the Doppler centroid frequency estimates (Chapron et al., 2005). The idea of exploiting these Doppler centroid anomalies of conventional SAR raw data for current retrievals was first proposed in the 1970's and 1980's (Shuchman, 1979; Madsen, 1989), but did not gain much attention until its demonstration with Envisat Advanced SAR (ASAR) data (Chapron et al., 2005). Consequently, since mid 2007, a grid of Doppler centroid frequencies has been included in the ASAR wide swath mode and wave mode products.

The challenge of verifying remotely sensed current observations is challenging and complex, but good qualitative agreement between SAR-derived surface currents and direct in situ current measurements from surface drifting buoys has been found (Johannessen et al., 2008; et al., 2011). However, at first order, the Doppler anomaly is mostly wind dependent, as revealed when collocated monthly wind fields from the European Centre for Medium Range Weather Forecasts (ECMWF) were projected along the radial direction of Envisat ASAR Wave Mode data. Based on the collocated data set obtained this way, a neural network model was created for incidence angles of $23^{\circ}$ and $33^{\circ}$ (Collard et al., 2008; Mouche et al., 2012). Using the ASAR wide swath mode, synoptic imaging of intense current regimes is also feasible provided reliable removal of the wind contribution to the Doppler signal is obtained (Johannessen et al., 2008) with residual line-of-sight velocities reaching more than $2 \mathrm{~m} \mathrm{~s}^{-1}$. A comprehensive description of the processing steps and error corrections needed to retrieve reliable surface velocity estimates from Envisat ASAR wide swath mode products is presented in Hansen et al. (2011).

\section{Currents from along-track Interferometry}

Within the last decade, considerable progress has been made in the development of along-track interferometry (ATI) for surface current observations. The ATI technique was first proposed by Goldstein and Zebker (1987) and subsequently demonstrated in several airborne experiments. 
The first space-borne demonstration was possible with the single-pass interferometric SAR system installed on space shuttle Endeavour for the Shuttle Radar Topography Mission (SRTM) in February 2000 (Rabus et al., 2003; Romeiser et al., 2010). In this case an along-track antenna distance of $7 \mathrm{~m}$ (in addition to the cross-track distance of $60 \mathrm{~m}$ ) provided surface current retrievals at a few test sites of opportunity. TerraSAR-X, launched in June 2007, has a programmable phased-array antenna panel that can be divided into two parts with a theoretical phase center distance of $2.4 \mathrm{~m}$. In both cases, the effective baseline is half the given distance, and the effective ATI time lags are clearly suboptimal (Romeiser and Runge, 2007), but the data have allowed the demonstration of current measurements from space by ATI. In particular,

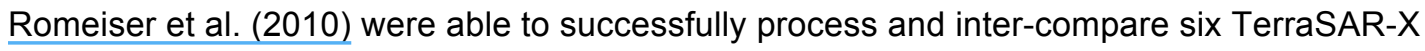
based Aperture-Switching (AS) mode images of the lower River Elbe (in Germany) with results from a numerical model. The results and comparison clearly demonstrates that the AS-mode data seem to be consistent with the model simulations, suggesting that the retrieval of absolute currents from the pure ATI data of TerraSAR-X is possible.

\section{The future and systematic sensor synergy}

A common theme through all of the previous sections has been SAR. Clearly spaceborne SAR has shown a unique capability to detect mesoscale-to-submesoscale eddies (10-50 km diameter) particularly in dynamically active coastal regions. Submesoscale eddies account for substantial mixing dynamics and eddy kinetic energy in the global oceans and play important roles related to nutrient availability and biological productivity. A synergistic approach for quantitative analysis of high resolution ocean SAR and imaging spectrometer data, including thermal infrared (IR) channels has been proposed by Kudryavtsev et al. (2012). They illustrated a direct link between surface observations and upper ocean flow characteristics. Example uses of such data would include monitoring ice dynamics and fisheries (where upwelled water could indicate high levels of nutrients but all higher concentrations of $\mathrm{CO}_{2}$ ). A logical next step would be to intelligently combine all of the techniques described here (e.g. SAR, altimetry, scatterometry and ocean colour techniques) to provide a 3D quantitative description of the upper ocean dynamics. This combination of approaches also holds the potential to produce more spatially and temporally complete observations, however, combining the observations of ocean currents from these different spatial and temporal scales and depths is likely to be challenging. New research that tackles this could enable the first direct observations of 3D and 
even 4D (3D + time) ocean circulation.

\section{Storm surges}

A storm surge is a transient phenomenon with a period of a few minutes to a few days of high sea level in a coastal or inland sea. They can result in significant loss of life, damage to infrastructure and property, and in some severe cases can result in the complete destruction of coastal communities. Storm surges are produced by severe atmospheric conditions associated with deep atmospheric low-pressure systems such as Tropical Cyclones or Extra-Tropical Cyclones e.g. Horsburgh et al. (2011). The change in water level associated with the deep atmospheric low-pressure at a given point in time is then modified by a variety of complex interactions between the storm surge itself and the local dynamic tidal characteristics, wind and swell waves, currents, and the effects of precipitation on rivers and estuaries.

Hydrodynamic ocean models initialised and forced by numerical weather prediction (NWP) and numerical ocean prediction (NOP) models, are the established way of forecasting storm surges e.g. Swail et al. (2010). Typically these storm surge forecasting and warning systems (as with most model forecast systems) use of in situ and satellite observations to verify the different components of the models output and/or the observations are directly assimilated into the model nowcasts. Satellite observations are also key for deriving disaster mitigation strategies, for example to identify where the surge energy may be focused. Key measurements for successful surge forecasting include timely and accurate observations of the storm track, water level, surface wind speeds and surface atmospheric pressure. Many of these observations, such as water level and surface wind speeds, have been available via satellite remote-sensing since the early 1990s (Figure 1). However, despite their availability, satellite observations have not been fully utilized by many storm-surge forecasting teams (ESA, 2010). This situation has encouraged researchers to develop, demonstrate and validate innovative satellite sensor based, or enhanced, techniques for improving storm surge applications in coastal zones (Harwood et al., 2013a).

\section{Current state of play for routine or operational storm surge models}

Numerical ocean prediction models used for providing ocean forecasts tend to be depth averaged 2-dimensional or 3-dimensional with several layers in the vertical dimension e.g. 
Horsburgh et al. (2011). Within these models the storm surge equations are usually solved on a structured grid, but the need for resolving complex coastlines and bathymetry have made the use of finite element and finite volume models popular e.g. Marshall et al. (1997). Such models typically use a triangular mesh that follows the coastlines.

Several countries prone to storm surges operate an explicit storm surge model setup, or as a substitute have access to output from a hydrodynamic model which has been forced with the output from a numerical weather prediction model. In some regions within the European Global Ocean Observing System (EUROGOOS), such as the North West European Shelf Operational Oceanographic System (NOOS, http://www.noos.cc/), the countries have initiated a cooperation with the aim to promote and develop an operational oceanographic infrastructure, including routine collection, interpretation and presentation of in situ and model data e.g. Holt (2006). This exchange of information is necessary in order to compare, validate and improve the storm surge forecasts and the service delivered to the public and authorities. Only one initiative (Harwood et al., 2013b) has explicitly exploited satellite observations within the actual surge model for near real-time storm surge forecasting.

\section{Recent advances}

The advances in the last 5-10 year with respect to using satellite and in situ observations in storm surge modelling have primarily been achieved by assimilating in situ tide gauge observations of water level. Different data assimilation techniques have been used to demonstrate improvements in the storm surge modelling, when compared to control runs (Verlaan et al., 2005; Peng and Xie, 2006; Sørensen and Madsen, 2004). Very few studies have directly assimilated satellite observations into storm surge models and then assessed the change in performance. This lack of exploitation of satellite data is due to the transient nature of the sea level and the often sparse spatio-temporal sampling characteristics of altimeter data. In addition, the coastal proximity of the surges has traditionally been challenging to the standard altimetry processing schemes (Vignudelli et al., 2011). New coastal altimetry products (Bouffard et al., 2008; Cancet et al., 2010; Cipollini et al., 2010; Passaro et al., 2014) have considerably reduced the errors in the altimetric observations close to the coast and the potential benefits of assimilating altimetry observations directly into surge models has now been documented

(Mourre et al., 2006; Le Hénaff et al., 2009). 
Statistical blending of tide gauge observations with altimetry observations (e.g. $\underline{\text { Høyer and }}$ Andersen (2003)) has been shown to produce a real-time hourly 2-D SSH field for the North Sea and Baltic Sea. These data are attractive as their accuracy is independent of the quality of the atmospheric forecast. In addition, the spatial spread of information from the coastal tide gauges is implicit in the field, which makes it easier for hydrodynamic models to assimilate. The original approach used standard altimetry observations (Høyer and Andersen, 2003; Madsen et al., 2007), but improved performance was recently obtained through the use of coastal specific altimetry data (Madsen et al., 2015).

A modelling study highlighted the potential improvements in the storm surge models that can be made using wide swath altimetry and in situ observations (Mourre et al., 2006).

More recently an impact assessment study was carried out by the Danish Meteorological Institute (DMI) within the European Space Agency eSurge project to demonstrate the impact of assimilating a blended tide gauge and altimetry dataset (Madsen et al., 2015). The observations for three storm surge events were assimilated resulting in a stable hydrodynamic ocean model. In general, the model runs confirmed that the model was dragged towards the blended observations during the assimilated runs. This was the first time that a blended tide gauge and altimetry dataset was assimilated directly into the ocean model and much experience was gained. Future assimilation runs are likely to focus on aspects like evaluating model errors as the assimilation frequency is varied. We anticipate that future applications of the statistical blending technique will initially focus on enabling more spatially extensive and accurate monitoring of enclosed or semi-enclosed seas, such as the Adriatic, which are prone to storm surges and where good tide gauge coverage currently exists.

\section{Future work within the use of satellite observations in storm surge modelling} Improvements in the Numerical Weather Prediction models are critical to improving storm surge forecasts. Clearly satellite observations also provide a unique and underexploited source of relevant observations for the storm surge modelling community. Near real-time and high quality satellite observations were shown in an initial study (Madsen et al., 2014) to be of value when assessing the quality of the storm surge model a surge event in 2013. The hydrodynamic storm surge model forecasted unprecedented high water levels in the Fjord of Roskilde (Denmark) 
several days in advance. Using the along-track satellite observations from Cryosat-2 for verification increased the confidence in the warnings that were issued (figure 4). This suggests that future storm surge forecasting systems should therefore make use of near-real time altimetry observations to assess the quality of forecasts, or at least use them to provide initial surge state estimation provided that the high quality data are available in near real-time. For initial state estimation, one approach would be to routinely use altimetry data to assess the accuracy of the tidal state model, the performance of which can impact the surge forecasts (Flowerdew et al., 2010).

Future satellite missions such as the Surface Water and Ocean Topography (SWOT) mission (Fu et al., 2010) and the EU Copernicus programme are likely to increase the uptake of satellite observations in the storm surge models, further improving their performance. Real time warning and forecasting of storm surges are likely to be become more important as future climate scenarios suggest increased storm frequency, inundation and sea level rise in many of the areas already impacted by storm surges (Stocker et al., 2013) and remote-sensing systems will provide the necessary synoptic monitoring capability required to deliver the necessary data to support prediction and monitoring of these systems in future.

[Figure 4 here]

\section{Sea ice}

Sea ice forms in the polar regions and consists of frozen seawater. During freezing the water molecules condense to a structure that is more open (less dense) than its liquid form and so the ice floats. Due to wind, current and temperature variability, sea ice is very dynamic and a wide variety of ice types and features can exist including frazil ice, slush, grease ice and pancake ice e.g. Wadhams (2000). Sea ice also has a very high albedo (compared to the liquid water of the open ocean) and forms a potential barrier to the exchange of heat, momentum, water vapour and gases such as $\mathrm{CO}_{2}$. The retreating sea ice and thus reduced albedo in the polar regions is thought to increase the amount of solar radiation absorbed by the oceans, leading to further warming (Deser et al., 2000). Therefore sea-ice is a crucial component of the climate system and a critical variable in global climate and Earth system models. Due to its dynamic nature the 
monitoring of sea ice is also important for shipping, oil and gas operations and increasingly for tourism. Changes in Arctic air temperature and sea ice type, cover and extent present new challenges for Arctic people and wildlife (Stirling and Derocher, 2012), and cause repercussions for weather systems at lower latitudes (Vihma, 2014). The continued reduction in the extent of summer sea ice and thickness has already modified human activities such as shipping and offshore exploration of fossil fuels due to longer ice-free periods (Burkett, 2011).

In situ data are essential to understand and monitor sea ice distributions but due to the inhospitable nature of the polar regions and their large extent, it is unwise to rely solely on spatially and often temporally sparse in situ measurements. Hence, altimeters, scatterometers, passive microwave and visible spectrum sensors are all used to study sea ice. The penetration of microwaves into the sea ice is determined by the permittivity and scattering of sea ice and the response depends on the brine and air within the ice. The sea ice surface changes seasonally, and as a result so does ice salinity, density, permittivity and scattering characteristics. Furthermore, old multi-season ice has a different emissivity (and thus spectral signature) from that of newly formed thin sea ice.

\section{Sea ice extent and total concentration}

Sea ice extent has been monitored by satellite microwave sensors since the 1970 s providing daily global coverage of the polar oceans. Sea ice data represent one of the longest satellite remote-sensing data records e.g.Stroeve et al. (2012). The strong contrast between the emissivity of sea ice and that of open water has also been exploited since the 1970s via the use of passive microwave data to provide reliable estimations of the total ice concentration. Efforts have been made to build long-term homogeneous time series of sea-ice extent data (e.g. US National Snow and Ice Data Center, European Ocean and Sea Ice Satellites Applications Facility) by combing estimates from several different algorithms and sensors e.g. (Helfrich et al., 2007; Meier et al., 2015). A recent study analysed existing algorithms and compared them to quantify uncertainties as a first step towards a multi-sensor merged dataset (Ivanova et al., 2014). This multi-sensor merged approach is now being developed within the European Space Agency Sea ice Climate Change Initiative project to increase temporal and spatial coverage whilst and towards improved characterisation of errors and uncertainties. 
Studies using these satellite derived sea ice extent datasets have shown a rapid decline of Arctic sea ice cover e.g. (Comiso et al., 2008) with a high variability in summer during the last decade and in particular in 2007 and 2012. The mean trend between 1978 until 2012 is estimated to $-3.8 \pm 0.3 \%$ loss per decade (Stocker et al., 2013) and the trend is larger in the summer and autumn mainly because of the rapid decline in the multi-year ice cover (Comiso, 2012).

\section{Sea ice thickness}

For many applications (e.g. ship routing and climate research) it is necessary to know sea ice thickness. For example, the combination of sea ice extent and thickness allows the estimation of the sea ice volume, an important variable for studying heat budgets, atmospheric circulation and thus projecting future climate (Tilling et al., 2015).

Sea ice thickness is studied using submarine sonar data, airborne surveys, in situ measurements and satellite observations e.g. Kwok and Rothrock (2009). However, the thickness estimates can be highly variable and can have high associated uncertainties depending on the area studied, the time period and the methodology used. The successful launches of more advanced satellite sensors, including ICESat-1 and Cryosat-2, is helping to reduce uncertainties in these thickness measurements through providing much richer and denser datasets, which is particularly important as the rate of decline in ice thickness appears to be increasing e.g. (Kwok and Rothrock, 2009).

Altimeter sensors, including RA2, ERS-1 and -2, Cryosat-2 and ICESat-1 (table 1) are the main instruments and sensors used for studying sea ice thickness. Recent work has shown that large-scale remote-sensing of snow depth on Antarctic sea ice utilizing passive microwave radiometers also shows promise (Kern et al., 2011). Ice or snow surface elevation can be estimated by comparing the altimeter return signal with that of a SSH reference signal within the satellite footprint (Laxon et al., 2003). Where possible, the sea surface elevation reference can be determined using new openings in the ice. This analysis is then adjusted for biases linked to snow sitting on top of the ice and to heterogeneous ice coverage within the satellite footprint. The result is a freeboard estimate that has to be converted to ice thickness. Thus the resulting satellite derived ice thickness estimate will invariably have high uncertainties associated with it 
since it depends on accurately estimating ice and snow densities. Snow depth can also present a significant uncertainty term for ice thickness retrieval from altimetry (Giles et al., 2007; Laxon et al., 2013).

During the last decade the Cryosat-2 sensor has been used widely in ice thickness research. The altimeter was specifically designed for sea ice freeboard measurements and is able to measure sea ice thicknesses that are $>1 \mathrm{~m}$. Recently work has also highlighted how novel Lband microwave data from the Soil Moisture and Ocean Salinity (SMOS, satellite launched in 2009), can be used to derive sea ice thickness during the annual Arctic freeze-up (Kaleschke et al., 2012). Sea ice thickness retrievals from SMOS useful for thin ice $(<1 \mathrm{~m})$ can then be used to complement the Cryosat-2 derived thick sea ice thickness estimate.

\section{Ice roughness and type}

The sensible heat flux from the ocean to the atmosphere is one to two orders of magnitude greater over thin ice than it is over thick multiyear ice; hence for many applications, especially meteorological and climate studies, the determination of the ice type is crucial. Multiyear ice is a parcel of ice that has survived the summer melt season. As sea ice ages, particularly as it passes through its first melt season, important physical properties of the ice change: the sea ice desalinates and deformational processes increase ice thickness. This freshening and thickening increases the probability that sea ice will survive the following melt season, as more heat would be required to melt the ice (Vancoppenolle et al., 2009). The study of the ice type surfaces shows that since the 2000 s there has been a reversal in the proportion of seasonal to multiyear ice types, with seasonal sea ice now covering more than two thirds of the Arctic Ocean in late winter. A sharp reduction of the multiyear ice fraction has also been observed (Comiso, 2012). In particular the multiyear ice in the central Arctic has decreased by more than 42\% since 2005 (Kwok et al., 2009). This decline was attributed to the near-zero replenishment of the multi-year ice in 2005 (Kwok, 2007).

Sea ice type can be deduced from satellite observations using various approaches. The majority of these are based on the variability of the sea ice roughness as a function of season and sea ice age (in months to years). Scatterometers, such as those onboard ERS-1, ERS-2, ASCAT, NSCAT and QuikSCAT, provide backscatter data that have a high sensitivity to the 
surface topography of ice and can be used to follow ice type evolution (Gohin et al., 1998). Data from these sensors can be used to detect and track the multiyear sea ice during the winter. For instance, Swan and Long (2012) used this approach to identify a temporal reduction in Arctic multi-year ice, in conjunction to an increase in first-year ice between 2003 and 2009. Alternatively, some techniques use a backscatter threshold to distinguish between multiyear and first year (or seasonal) ice (Swan and Long, 2012). Some approaches use combined data from satellites and buoys to track individual sea ice parcels from their formation until they disappear via melt or transport out of the polar waters (Maslanik et al., 2011). Recent research has also shown that improvements to automatic sea ice classification are possible by using high resolution SAR data e.g. Zakhvatkina et al. (2013).

\section{Sea ice motion and displacements}

Sea ice motion is mainly driven by winds and currents but its motion is also dependent on the ice concentration and type. Large spatial scale ice motion data are useful for supporting shipping and exploration, and validating ice and climate models. Land encircles much of the sea-ice in the Arctic restricting its large-scale movement, but sea-ice motion influences the export of sea ice to the Atlantic ocean which mainly occurs through the Fram Strait. In Antarctica there are no land boundaries to contain the ice, so the sea-ice tends to flow northwards until it melts. Research in this area is well developed and has focussed on deriving sea ice displacement from scatterometer and radiometer data and the use of models. Example satellite sensors include the Special Sensor Microwave Imager (SSM/l), the Advanced Scatterometer (ASCAT) at low spatial resolution, the Advanced Microwave Scanning Radiometer 2 (AMSR-2) at medium, and various SAR sensors at high spatial resolution). As a result ice displacement fields are now routinely available through various operational or archiving portals for Arctic and Antarctic waters e.g. Kwok (2010); Girard-Ardhuin and Ezrat (2012) and the U.S. National Snow and Ice Data Centre. Such data in conjunction with buoy data have highlighted the increase in recent years of ice displacement in the Arctic (Kwok et al., 2013; Rampal et al., 2009), an observation which is consistent with an overall decrease in thicker multi-season ice from other studies. 


\section{Future sea ice research and monitoring}

Observations of key sea ice parameters have been possible using satellite EO for the last four decades and sea ice monitoring is now highly dependent on the use of satellite data. Climate change studies require long-term homogeneous time series for initiating and verifying model forecasts, which is only possible by merging data from multiple satellite sensors. At present, several projects and/or data centres are working to provide these synergistic datasets; a difficult task due to the need for inter-sensor calibrations, the different kinds of sensors used, and the different resolution and accuracy of historical data (e.g. http://nsidc.org and Levinson et al. (2015)). In particular multiyear ice extent datasets are likely to benefit from algorithms and methods that combine radiometer and scatterometer data, as they have the potential to improve and extend the current time series. A longer high-quality time series of the multiyear ice extent would also support developments in sea ice thickness retrieval by permitting an improved choice of sea ice densities (Laxon et al., 2013). An important next step would be to fully characterise and then reduce the associated uncertainties for sea ice parameters during the highly dynamic and variable melt season; a particularly important period for Arctic biological activity and a time when shipping routes begin to become navigable again.

The merging of sea ice thickness estimates from multiple sensors to provide a more comprehensive sea ice thickness distribution, that includes both thin ice thickness estimates and those of thicker ice inferred from altimetry, appears to be possible, but reliable snow depth and sea ice densities would still be needed to improve the estimate of this thickness. Marginal ice zone parameters, for example those describing wave-ice interactions, need to be better understood and quantified since this is where exchanges between air, ocean and ice are the most complex. Finally, the study of ice displacement will no doubt benefit from the large increase in near real-time SAR data that are now becoming available from Sentinel-1A following its launch in early 2014.

\section{Atmosphere-ocean gas fluxes}

The ocean and atmosphere are major components of the Earth's surface, with reactions within and between them controlling many of the properties of the Earth's system. The atmosphere- 
ocean (air-sea) interface represents a vital link between the oceans and the atmosphere by acting as the conduit for the transfer of heat, momentum, aerosols, and gases between the two phases; this transfer of gases, for example oxygen $\left(\mathrm{O}_{2}\right)$ and carbon dioxide $\left(\mathrm{CO}_{2}\right)$, is of fundamental importance for many processes including our climate, food security and human health (Nightingale, 2009).

The air-sea exchange of carbon dioxide $\left(\mathrm{CO}_{2}\right)$ has received the most attention amongst marine gases, partly because the net flux of $\mathrm{CO}_{2}$ from the atmosphere to the ocean represents about a third of the annual release of anthropogenic $\mathrm{CO}_{2}$ to the atmosphere (Sabine et al., 2004; Le Quere et al., 2013) and because this flux is superimposed on a much larger natural exchange of $\mathrm{CO}_{2}$ that is cycled annually between the ocean and atmosphere (Watson and Orr, 2003). More recently there has been an increasing awareness that the net flux of $\mathrm{CO}_{2}$ into the ocean is reducing the $\mathrm{pH}$ of the world's surface oceans (Santana-Casiano et al., 2007), a phenomenon know as ocean acidifcation. The effect of this on marine biota and productivity (Riebesell and Tortell, 2011) and possible feedbacks to the atmosphere via alterations to the exchange of climate-active gases across the air-sea interface are as yet unclear (Hopkins et al., 2011).

The air-sea flux of gases is controlled by wind speed, sea state, sea surface temperature, salinity, solubility of the gases and surface processes including any biological activity (figure 5). A detailed overview of all of these processes and their interactions is given by Wanninkhof et al. (2009) and Garbe et al. (2014). Many of the processes shown in figure 5 can either be directly monitored from satellite remote-sensing (e.g. emitted infrared radiation, wind speed and direction, precipitation rates, sea ice coverage, wind stress, salinity) or proxies can be used to infer their existence and variability (e.g. biological surfactants and dust).

Most air-sea gas flux estimates depend on a calculation using a standard bulk air-sea gas transfer scheme e.g. as used in Takahashi et al. (2009). For each gas, this calculation depends upon measurements of the gas concentration in both the surface ocean and the lower atmosphere, and upon formulae and resulting "transfer coefficients" that describe the "rate constants" for transfer across the sea surface. The simplest model of air-sea gas transfer is the two-film model (Liss and Slater, 1974; Whitman, 1923) and the reader can refer to the references therein for a full explanation of the transfer process of different gases. Dependent 
upon the gas of interest, water-side gas transfer or air-side gas transfer may dominate, which will depict the complexity of the gas transfer coefficient. $\mathrm{CO}_{2}$ is considered an insoluble gas and so the air-sea flux can be determined using a single (water-side) gas transfer velocity, $k$ :

$F=k\left(\alpha_{w} p \mathrm{CO}_{2 w}-\alpha_{s} p \mathrm{CO}_{2 a}\right)$

where $\alpha$ is the solubility of the gas in water at depth $\left(\alpha_{w}\right)$ and at the sea skin $\left(\alpha_{s}\right), p \mathrm{pO}_{2}$ is the partial pressure of $\mathrm{CO}_{2}$ in the water $\left(p \mathrm{CO}_{2 w}\right)$ and air $\left(p \mathrm{CO}_{2 a}\right)$. Equation 1 can be modified to be applicable to other insoluble gases including nitrous oxide $\left(\mathrm{N}_{2} \mathrm{O}\right)$, oxygen $\left(\mathrm{O}_{2}\right)$ and methane $\left(\mathrm{CH}_{4}\right)$. Air-side controlled gases (soluble gases), where $k$ needs to be parameterised using both water-side and air-side components, include dimethyl-sulphide $\left(\mathrm{CH}_{3}-\mathrm{S}-\mathrm{CH}_{3}\right.$ or DMS) and sulphur dioxide $\left(\mathrm{SO}_{2}\right)$. Satellite remote-sensing can be used to study or parameterise various components of equation 1 and it can also be used to help understand the results from in situ based gas flux studies. These different aspects are now described.

[Figure 5 here]

1 Estimating air-sea $\mathrm{CO}_{2}$ gas fluxes using remote-sensing

Relevant satellite remote-sensing data for air-sea gas flux studies include sea surface temperature, chlorophyll-a, surface salinity, sea surface roughness and wind speed data. These datasets are generally used to determine the gas transfer velocity, solubility and to correct in situ based climatology datasets to allow the determination of appropriate $\mathrm{pCO}_{2 w}$ and $p \mathrm{CO}_{2 a}$ values (Fangohr and Woolf, 2007; Fangohr et al., 2008; Land et al., 2013; Else et al., 2008). Currently it is not possible to derive all of the required variables from satellite observations. Hence studies will typically use a combination of satellite remote-sensing data, in situ and model derived data to derive air-sea gas fluxes at the global, basin and regional scales. Despite this limitation the improved quasi-global availability of EO data has facilitated recent studies of $\mathrm{CO}_{2}$ air-sea exchange over a substantial area of the Arctic Seas (Else et al., 2008; Arrigo et al., 2010; Land et al., 2013), Atlantic Ocean (Kettle and Merchant, 2005; Kettle et al., 2009) and global oceans (Fangohr et al. (2008) and figure 6a). 
Many regional studies have used a range of satellite remote-sensing datasets (most notably SST, chlorophyll) to estimate $\mathrm{pCO}_{2 w}$ based on regional empirical algorithms derived from in situ data. For example, Else et al. (2008) used this approach to estimate $p \mathrm{CO}_{2 w}$ in Arctic waters using SST data. This sort of approach can be useful for investigating the spatial variability in $p \mathrm{CO}_{2 w}$ around an in situ study site, allowing for an estimate of the localised integrated fluxes to be calculated. However the applicability of these approaches across differing oceanic regimes and time periods is unclear. The complex and varying nature of the carbonate system suggests that this sort of approach is only really suitable for regional and temporally limited studies.

It is considered that the wind is the main motor of air-sea gas exchange, but it is a challenge to optimize gas transfer velocities $(k)$ are estimated from wind-related data alone. Most existing gas transfer parameterisations use wind speed and these are often applied at regional or global scales using remote-sensing retrievals of wind speed (Fangohr et al., 2008; Boutin et al., 2002). All retrievals of wind speed from passive and active microwave instruments rely on surface roughening by the wind. The backscatter measured by scatterometers and SAR is primarily based on roughness at a Bragg wavelength. So it is possible that the use of wind speed estimates, derived via backscatter relationships, introduces unknown errors into the resulting gas transfer velocity estimates. For example, some satellite data processing methods use model derived wind speeds to correct or smooth the output from backscatter relationships, so localised changes in the surface roughness (potentially of interest for gas flux research) can be lost. The reliance on wind speed parameterisations in part originated due to wind speed being a common parameter that is measured on board research ships. Some studies have identified mean square slope as a suitable alternative to that of using wind speed e.g. (Goddijn-Murphy et al., 2013). Since the backscatter at nadir is closely related to mean square slope, there is a theoretical advantage in directly relating altimeter backscatter to transfer velocity. Theory suggests that through using dual altimeter returns it becomes possible to isolate the wave lengths of interest for gas exchange (Glover et al., 2002). Altimeters on board satellites can also provide twenty years of data and therefore are a strong resource for the development of gas flux climatologies (Glover et al., 2007; Glover et al., 2002). The linear relation between mean square slope and $k$, as found in laboratory studies using a wave tank, has been applied to remote-sensing $k$ algorithms (Glover et al., 2002; Fangohr et al., 2008; Goddijn-Murphy et al., 
2012; Goddijn-Murphy et al., 2013) and a recent study has shown that a dual frequency approach has lower average errors than using wind speed data (Goddijn-Murphy et al., 2013). It is an open question, whether it is better to persist with wind speed (which at least is widely available and well understood) or to develop methods that require retrievals of other parameters. Therefore often studies will use both techniques to gain a better understanding of the total uncertainty and error in using remote-sensing derived gas transfer (Fangohr and Woolf, 2007; Land et al., 2013).

\section{Remote-sensing for supporting in situ gas flux studies}

All of the studies in section 5.1 have used satellite remote-sensing data to estimate components of the gas flux parameterisation (e.g. equation 1 and its soluble gas variant). A range of studies have also used satellite remote-sensing to aid the understanding of gas flux data (e.g. figure 6b), as a proxy for in situ data that were not collected at the time of a research campaign, to replace in situ data that contained known errors, or to determine the suitability or sensitivity of the in situ data to describe the larger spatial and temporal variations.

Previous attempts to study the effects of biological slicks in relation to gas transfer velocity were hampered by i) the lack of co-incident SAR/altimetry and optical (visible and thermal infra-red) data in slick regions and ii) the complexity of using satellite data to detect slicks (Potter et al., 2007). Some studies e.g. (Woolf and Ufermann, 2005; Tournadre et al., 2006; Woolf and Gommenginger, 2008) have suggested that there is an apparent change to the altimetry return that could be exploited to determine areas of slicks. A further study suggested that the altimeter-derived gas transfer velocity was reduced in known areas of biological slicks (Fangohr and Woolf, 2007). However, it was unclear whether the detected reduction in gas transfer velocity in these areas was due to biological activity or another factor. All of this work prompted Salter et al. (2011) to used historical remote-sensing derived primary production data as a proxy for surfactant coverage to reanalyse historical in situ cruise data. This methodology allowed the authors to identify which in situ gas transfer velocity data were likely to be impacted by surface biological processes. The study also describes a field experiment in which the deliberate release of a surfactant in the North Atlantic significantly reduced the air-sea transfer of DMS and the helium/sulphur hexafluoride tracer pair, at wind speeds of up to $10 \mathrm{~ms}^{-1}$. The work provided field evidence that gas transfer is suppressed by biologically derived surfactants, providing 
further support to the need to derive gas transfer velocities from surface roughness data (e.g. radar backscatter), rather than relying solely on wind speeds.

Work by Ho et al. (2006) used remotely sensed scatterometer derived wind data in place of their in situ wind data, as the in situ data were deemed to be distorted due to the air flow over the ship. Shutler et al. (2013) used visible spectrum remotely sensed derived phytoplankton estimates to investigate how coccolithophores, a calcifying plankton, can modulate the localised and integrated net air-sea $\mathrm{CO}_{2}$ fluxes in the Atlantic ocean.

\section{Future air-sea gas flux work}

Thus far all of the gas flux studies described have focused on $\mathrm{CO}_{2}$ as the major target gas species of interest. The ability to parameterise soluble gases can also aid the study of insoluble ones. For example, the non-bubble component of gas transfer can be calibrated using soluble gas data (e.g. DMS) and then the result applied to insoluble $\mathrm{CO}_{2}$ (Goddijn-Murphy et al., 2012). Cycles in the natural world are also intimately linked; for instance the nitrogen and carbon cycles, so understanding the behaviour of $\mathrm{N}_{2} \mathrm{O}$ for example can support the interpretation of $\mathrm{CO}_{2}$ data. $\mathrm{CH}_{4}$ and $\mathrm{N}_{2} \mathrm{O}$ are both climatically important gases and they are both water-side controlled gases, therefore equation 1 can be used to parameterise the gas flux. Fortunately both of these gases have similar gas transfer velocity parameterisations to that of $\mathrm{CO}_{2}$; indeed $\mathrm{CO}_{2}$ transfer velocity parameterisations and data are often used to study $\mathrm{N}_{2} \mathrm{O}$ e.g. (Rees et al., 2011). However, to date there have been few studies for other gases that have made use of satellite remote-sensing data. Part of the reason for this is the lack of suitable in situ databases of in-water fugacity measurements of these gases. However, international efforts are currently focussed on collating climatologies of these different gases (Bange et al., 2009; Kock and Bange, 2015). Until these datasets are publically available the potential of satellite remotesensing derived fluxes of these other gases is limited to regional and short-term studies where individual scientists have collected suitable in situ data. The exception to this is the predominantly water-side controlled gas DMS. A relatively large in situ climatology of in-water DMS concentrations already exists (Lana et al., 2011) and recent work has developed methods for using this climatology and satellite remotes sensing (altimeter derived wind and mean square slope, and SST) data to study global sea-air DMS fluxes (Land et al., 2014; GoddijnMurphy et al., 2012). 


\section{Surface heat fluxes via phytoplankton and visible spectrum ocean colour data}

The surface exchange of heat and momentum is responsible for the dynamic circulation of the atmosphere and oceans. Heat fluxes in the surface layers of the ocean result from two opposing processes: that of direct heating by the sun, which tends to promote vertical stratification; and that of mixing by wind, which tends to erode stratification (figure 5). For the purpose of modelling heat flux, the solar irradiance is usually treated as the sum of two components: a near-infra-red component, whose path length in the ocean is only a few millimetres (the non-penetrating part), and a component with a much longer path length (the penetrating part), covering approximately the visible spectrum. Energetically, the two components are roughly equal in magnitude.

Satellite measurements of ocean colour provide global data on the distribution of phytoplankton in the ocean. These data, when combined with a model of light penetration in the ocean, provide an avenue for modelling the distribution of solar radiation in the surface layers of the ocean, and its contribution to the heat budget and to heat fluxes across the air-sea interface. Table 1 gives a brief summary of the range of topics in heat fluxes to which ocean-colour data can make a useful contribution.

[Table 1 here]

The principal absorber of visible light in the open ocean are phytoplankton along with associated detritus and dissolved organic matter. This absorption is often parameterised as a function of chlorophyll, the major phytoplankton pigment. Chlorophyll concentration is the one of the main products that can be retrieved from remote-sensing by visible spectral radiometry (ocean colour). Chlorophyll absorbs light principally in the waveband from 400 to $700 \mathrm{~nm}$, which is therefore called the range of photosynthetically active radiation (PAR). Chlorophyll and water molecules compete for photons in this range. The destiny of the energy absorbed by either water or phytoplankton is to be dissipated as heat (thereby raising the temperature of the water). Even the small proportion of the energy absorbed by chlorophyll that is used for photosynthesis ( $1 \%$ or less) is eventually lost as heat through the process of respiration. 
Chlorophyll concentrations found in the marine environment are logarithmically distributed.

Given a diffuse vertical attenuation coefficient for seawater of $0.04 \mathrm{~m}^{-1}$ over the domain of PAR, we can calculate that the attenuation coefficient will become double this value when chlorophyll concentration reaches $0.5 \mathrm{mg} \mathrm{m}^{-3}$. Considering the photic zone as a unit, and averaging the absorption over that zone, we find that phytoplankton and water will compete equally for photons at a chlorophyll concentration of about $2 \mathrm{mg} \mathrm{m}^{-3}$ (see Sathyendranath and Platt (1988), their Table 1).

Bulk models of mixed-layer dynamics in the ocean solve for the balance between the stratifying and mixing tendencies of solar heating and wind stress, respectively. From this balance, we can deduce the depth and the temperature of the surface mixed layer (Sathyendranath et al., 1991; Edwards et al., 2001). Absorption by phytoplankton (and associated material) will dominate the heating term in high-chlorophyll waters. At higher chlorophyll concentrations, solar heating will be concentrated in a smaller depth interval (favouring a shallower mixed layer) than at lower concentrations. In other words, the presence of phytoplankton confines solar heating of the ocean closer to the surface than would be the case in their absence.

The depth of the mixed layer affects the potential growth rate of phytoplankton in the layer. In a shallow layer, through which phytoplankton cells are mixed, the average light intensity experienced by the cells will be greater that in a deeper mixed layer. Phytoplankton growth occurs through photosynthesis, which is a process forced by light: all other things being equal, growth conditions in a shallow mixed layer will be more favourable than those in a deeper mixed layer. The possibility therefore exists for a positive feedback between increasing chlorophyll concentration and increasing SST (Sathyendranath and Platt, 2007), a mechanism that is more likely to occur in Spring in temperate latitudes, in association with the vernal bloom of phytoplankton. It can modify the seasonality (phenology) of phytoplankton in these latitudes (Sathyendranath and Platt, 2000). Wu et al. (2007) showed that, as well as advancing the phenology, the influence of phytoplankton on the seasonal progression of mixed-layer temperature and depth was such as to increase the maximum SST for the year by $1.5^{\circ} \mathrm{C}$ in the Labrador Sea, and $2.5^{\circ} \mathrm{C}$ over the Grand Bank of Newfoundland. Gnanadesikan et al. (2010) studied the impact of bio-optical heating on cyclone activity in the tropical Pacific. 
Horizontal gradients in the chlorophyll field can also lead to modification of both the horizontal circulation and the vertical circulation (Edwards et al., 2001). Fronts in the chlorophyll field are commonly seen in ocean-colour imagery. Physically, there will be an imbalance in solar heating rates across the front: the biomass-rich side will be heated more at the surface than the lowbiomass side, resulting in a density discontinuity across the front, perturbing the frontal circulation. The horizontal velocities along the front are $\sim 2 \mathrm{~cm} \mathrm{~s}^{-1}$. Therefore the vertical velocities are roughly $0.2 \mathrm{~mm} \mathrm{~s}^{-1}$, which is potentially significant for re-supply of nutrients at the front.

In brief, there is considerable evidence that variability in the optical properties of the ocean has an impact on the distribution of solar-induced heating of the ocean. In the open ocean, optical variability is determined largely by variability in phytoplankton and associated material, such as coloured dissolved organic matter and coloured detrital matter. However, such effects are yet to be included in a routine manner into models of ocean heat fluxes or into studies of biologicalphysical coupling in Earth system models, though such models are now emerging (e.g. Kim et al. (2015)) and they are being incorporated increasingly into biogeochemical and ecosystem models of the ocean e.g. Dutkiewicz et al. (2015). Further work in this area is likely to have major impacts on our capability to predict how global circulation may change in the future.

\section{Discussion}

Many of the research areas and applications presented in this review would benefit from the provision of long-term datasets. As such the European Union Copernicus programme (formerly known as the Global Monitoring for Environment and Security, GMES, programme) offers a huge opportunity. This programme has started and will provide a long term (15+ years) monitoring capability for the marine environment (Aschbacher and Milagro-Pérez, 2012). The space component of this programme is formed by a fleet of satellites called the Sentinels, most of which are designed to monitor different aspects of the oceans and atmosphere. For instance, Sentinel 1 carries an advanced SAR instrument (Torres et al., 2012) and Sentinel 3 carries a radar altimeter, and visible and thermal infrared instruments (Donlon et al., 2012). 
The development of the Global Navigational Satellite Systems-Reflectrometry (GNSS-R) promises to provide advances in wind speed and wave monitoring (Clarizia et al., 2014). GNSS$\mathrm{R}$ is a relatively new concept that exploits existing data from GNSS systems including the European Galileo and US Global Positioning System (GPS) systems by turning them into a bistatic radar system. The main advantages of GNSS-R lie in the global availability of GNSS signals, which provides a dense coverage over the Earth and offers the potential for significant improvements in spatio-temporal sampling of the ocean winds and waves. The receiver needed to capture the surface reflections is small and cheap, low-weight/low-power, and can be easily accommodated on small satellites or satellites of opportunity, thus reducing the cost of a mission and allowing for constellations of multiple GNSS-R receivers (Clarizia et al., 2014). The GNSS-R capability is already present on some satellites including the UK Disaster Monitoring Constellation (DMC) satellite.

NASA has recently launched two remote-sensing instruments to be mounted on the International Space Station (ISS). The space station is also a satellite, and so provides a unique low Earth orbit platform on which to mount sensors. Its orbit pattern ( 6 orbits a days over equatorial to mid latitudes) provides a unique viewing position for cyclones and hurricanes. The space station already carries a visible spectrum sensor (the hyper-spectral imager for the coastal oceans, HICO) and the ISS-RapidSCAT, which is a scatterometer designed to provide data for climate research, weather predictions and hurricane monitoring. A further instrument planned for the space station, the Cloud-Aerosol Transport System (CATS), may also prove useful for oceanography, if only to improve the quantification of atmospheric effects on other types of remotely sensed oceanographic data.

The creation and exploitation of miniature satellite constellations (e.g. femto-, pico-, nano-, micro and mini-satellites), such as the programme being developed and released by the US PlanetLabs start-up company, are likely to provide the scientific and operational communities with new datasets suitable for studying and monitoring physical oceanography. The launching of collections of miniature satellites (i.e. more than 20 in orbit at any one time) could enable submonthly processes to be monitored and characterised. The PlantLabs satellites are being developed to carry simple optical camera systems, and early data releases from these satellites 
suggest that the data could be exploited to study surface ocean currents, sea-ice, and heat fluxes, using some of the methods described in sections 2,3 and 6 of this review.

\section{Conclusions}

Our ability to monitor the physical characteristics and features of our oceans is imperative to help us understand and predict our climate, to support the search and provision of energy, and to support sustainable food harvesting and production. In this paper we have provided an overview of how the different remote-sensing techniques and approaches can be used to observe the physical properties of our oceans. We have then critically reviewed recent advances in how these observations are being used to understand, quantify and monitor surface currents, storm surges, sea-ice, atmosphere-ocean gas fluxes and surface heat fluxes. We highlight that satellite remote-sensing clearly has a significant role to play in these scientific areas by providing large spatial scale observations and measurements. However, satellite remote-sensing cannot be used in isolation, so the use of in situ and model data in conjunction with satellite remote-sensing data is key to enabling the full exploitation of these space-based observations. The current drive to establish long-term monitoring capabilities through commercial enterprises and government (agencies and policy) will underpin our future ability to provide regular and routine monitoring of our oceans. Novel platform and technology developments, including GNSS-R, commercial nano-satellites and the International Space Station will continue to provide us with new perspectives and ways of monitoring our oceans.

\section{Funding acknowledgement}

This work was supported by the European Space Agency [grant numbers 4000110778/14/I-BG, 4000112091/14/I-LG, 4000109513/13/I-LG, 4000103880/11/I-LG, 4000111424-14-IAM, 4000104733/11/I-AM]. The authors would also like to thank an anonymous reviewer who provided insightful feedback and guidance on the preparation of this manuscript.

\section{References}


Alpers W and Hennings I. (1984) A theory of the imaging mechanism of underwater bottom topography by real and synthetic aperture radar. Journal of Geophysical Research 89: 10529-10546.

Arrigo KR, Pabi S, van Dijken GL, et al. (2010) Air-sea flux of CO2 in the Arctic Ocean, 19982003. Journal of Geophysical Research 115.

Aschbacher J and Milagro-Pérez MP. (2012) The European Earth monitoring (GMES) programme: Status and perspectives. Remote Sensing of Environment 120: 3-8.

AVISO. (2015) http://www.aviso.oceanobs.com/en/data/products/oceanindicators-products/mean-sea-level.htm.

Bange HW, Bell TG, Comejo M, et al. (2009) MEMENTO: a proposal to develop a database of marine nitrous oxide and methane measurements. Environmental Chemistry 6: 195-197.

Bouffard J, Vignudelli S, Cipollini P, et al. (2008) Exploiting the potential of an improved multimission altimetric data set over the coastal ocean. Geophysical Research Letters 35.

Boutin J, Etcheto J, Merlivat L, et al. (2002) Influence of gas exchange coefficient parameterisation on seasonal and regional variability of $\mathrm{CO}_{2}$ air-sea fluxes. Geophysical Research Letters 29.

Burkett V. (2011) Global climate change implications for coastal and offshore oil and gas development. Energy Policy 39: 7719-7725.

Cancet M, Birol F, Roblou L, et al. (2010) CTOH regional altimetry products: examples of applications. OceanObs 2009: Sustained Ocean Observations and Information for Society. 306.

Cazenave A, Dominha K, Guinehutb S, et al. (2009) Sea level budget over 2003-2008: A reevaluation from GRACE space gravimetry, satellite altimetry and Argo. Global and Planetary Change 65: 83-88.

Chapron B, Collard F and Ardhuin F. (2005) Direct measurements of ocean surface velocity from space: Interpretation and validation. Journal of Geophysical Research 110.

Chelton DB, Schlax MG, Samelson RM, et al. (2007) Global observations of large oceanic eddies. Geophysical Research Letters 34.

Cipollini P, Benveniste J, Bouffard J, et al. (2010) The role of altimetry in coastal observing systems. OceanObs 2009: Sustained Ocean Observations and Information for Society. 
Clarizia MP, Ruf CS, Jales P, et al. (2014) Spaceborne GNSS-R minimum variance wind speed estimator. IEEE Transactions On Geoscience And Remote Sensing 52: 6829-6843.

Collard F, Mouche A, Chapron B, et al. (2008) Routine high resolution observation of selected major surface currents from space. In Proceedings SeaSAR 2008. ESA Publication Division.

Comiso JC. (2012) Large decadal decline of the Arctic multiyear ice cover. Journal of Climate 25.

Comiso JC, Cavalieri DJ and Markus T. (2003) Sea ice concentration, ice temperature, and snow depth, using AMSR-E data. IEEE Transactions On Geoscience And Remote Sensing 41: 243-252.

Comiso JC, Parkinson CL, Gersten R, et al. (2008) Accelerated decline in Arctic sea ice cover. Geophysical Research Letters 35.

Crocker RI, Matthews DK, Emery WJ, et al. (2007) Computing Coastal Ocean Surface Currents From Infrared and Ocean Color Satellite Imagery. Geoscience and Remote Sensing 45: 435-447.

da Silva JCB, New AL and Magalhaes JM. (2009) Internal solitary waves in the Mozambique Channel: Observations and interpretation. Journal of Geophysical Research 114.

de Souza RB, Mata MM, Garcia CAE, et al. (2006) Multi-sensor satellite and in situ measurements of a warm core ocean eddy south of the Brazil-Malvinas Confluence region. Remote Sensing of Environment 100: 52-66.

Deser C, Walsh JE and Timlin ST. (2000) Arctic sea ice variability in the context of recent atmospheric circulation trends. Journal of Climate 13: 617-633.

Donlon CJ, Berruti B, Buongiorno A, et al. (2012) The Global Monitoring for Environment and Security (GMES) Sentinel-3 mission. Remote Sensing of Environment 120: 37-57.

Ducet N, Le Traon P-Y and Reverdin G. (2000) Global high-resolution mapping of ocean circulation from TOPEX/Poseidon and ERS-1 and -2. Journal of Geophysical Research 105: $19477-19498$.

Dutkiewicz S, Hickman AE, Jahn O, et al. (2015) Capturing optically important constituents and properties in a marine biogeochemical and ecosystem model. Biogeosciences 12: 4447-4481.

Edwards AM, Platt T and Wright DG. (2001) Biologically induced circulation at fronts. Journal of Geophysical Research 106: 7081-7095. 
Edwards AM, Wright DG and Platt T. (2004) Biological heating effect of a band of phytoplankton. Journal of Marine Systems 49: 89-103.

Else BGT, Yackel JJ and Papakyriakou TN. (2008) Application of satellite remote sensing techniques for estimating air-sea $\mathrm{CO} 2$ fluxes in Hudson Bay, Canada during the ice-free season. Remote Sensing of Environment 112: 3550-3562.

Emery WJ, Thomas AC, Collins MJ, et al. (1986) An objective method for computing advective surface velocities from sequential infrared satellite images. Journal of Geophysical Research 91: 12865-12878.

ESA. (2010) ESA Storm Surge (eSurge) Demonstration Service: User Requirements Document. European Space Agency.

Fangohr S and Woolf DK. (2007) Application of new parameterizations of gas transfer velocity and their impact on regional and global $\mathrm{CO}_{2}$ budgets. Journal of Marine Systems 66: 195-203.

Fangohr S, Woolf DK, Jeffery CD, et al. (2008) Calculating long-term global air-sea flux of carbon dioxide using scatterometer, passive microwave, and model re-analysis wind data. Journal of Geophysical Research 113.

Flowerdew J, Horsburgh K, Wilson C, et al. (2010) Development and evaluation of an ensemble forecasting system for coastal storm surges. Quarterly Journal of the Royal Meteorological Society 136: 1444-1456.

Fratantoni DM and Glickson DA. (2002) North Brazil current ring generation and evolution observed with SeaWiFS. Journal of Physical Oceanography 32: 1058-1074.

Fu L-L. (2007) Interaction of mesoscale variability with large-scale waves in the Argentine Basin. Journal of Physical Oceanography 37.

Fu LL, Alsdorf D, Rodriguez E, et al. (2010) The SWOT (Surface Water and Ocean Topography) Mission: spaceborne radar interferometry for oceanographic and hydrological applications. OceanObs 2009: Sustained Ocean Observations and Information for Society.

Gabarró C, Font J, Camps A, et al. (2004) A new empirical model of sea surface microwave emissivity for salinity remote sensing. Geophysical Research Letters 31.

Garbe CS, Rutgersson A, Boutin J, et al. (2014) Transfer across the air-sea interface. In: Liss PS and Johnson MT (eds) Ocean-Atmosphere Interactions of Gases and Particles. 55144. 
Giles KA, Laxon SW, Wingham DJ, et al. (2007) Combined airborne laser and radar altimeter measurements over the Fram Strait in May 2002. Remote Sensing of Environment 111: 182-194.

Girard-Ardhuin F and Ezrat R. (2012) Enhanced Arctic sea ice drift estimation merging radiometer and scatterometer data. IEEE Transactions On Geoscience And Remote Sensing 50: 2639-2648.

Glover DM, Frew NM and McCue SJ. (2007) Air-sea gas transfer velocity estimates from the Jason-1 and TOPEX altimeters: Prospects for a long-term global time series. Journal of Marine Systems 66: 173-181.

Glover DM, Frew NM, McCue SJ, et al. (2002) A multiyear time series of global gas transfer velocity from the TOPEX dual frequency, normalised radar backscatter algorithm: American Geophysical Union.

Gnanadesikan A, Emaneul K, Vecchi GA, et al. (2010) How ocean color can steer Pacific tropical cyclones. Geophysical Research Letters 37.

Goddijn-Murphy L, Woolf DK, Bertrand C, et al. (2013) Improvements to estimating the air-sea gas transfer velocity by using dual-frequency altimeter backscatter. Remote Sensing of Environment 139.

Goddijn-Murphy L, Woolf DK and Marandino CA. (2012) Space-based retrievals of air-sea gas transfer velocity using altimeters: Calibration for dimethyl sulphide. Journal of Geophysical Research 117.

Gohin F, Cavanié A and Ezraty R. (1998) Evolution of the passive and active microwave signatures of a large sea ice feature during its 2.5 year drift through the Arctic ocean. Journal of Geophysical Research 103: 8177-8189.

Goldstein RM and Zebker HA. (1987) Interferometric radar measurement of ocean surface currents. Nature 328: 707-709.

Guymer TH, Quartly GD and Srokosz MA. (1995) The effects of rain on ERS-1 radar altimeter data. Journal of Atmospheric and Oceanic Technology 12: 1229-1247.

Hansen MW, Johannessen JA, Dagestad KF, et al. (2011) Monitoring the Surface Inflow of Atlantic Water to the Norwegian Sea Using Envisat ASAR. Journal of Geophysical Research 116.

Harwood P, Cipollini P, Snaith H, et al. (2013a) Earth Observation in aid of surge monitoring and forecasting: ESA's eSurge Project. EGU General Assembly. 11942. 
Harwood P, Cipollini P, Snaith H, et al. (2013b) Earth Observation in aid of surge monitoring and forecasting: ESA's eSurge Project. EGU General Assembly Conference Abstracts. Vienna, 11942.

Helfrich SR, McNamara D, Ramsay BH, et al. (2007) Enhancements to and Forthcoming Developments To the Interactive Multisensor Snow and Ice Mapping System (IMS). Hydrological Processes 21: 1576-1586.

Ho DT, Law C, Smith MJ, et al. (2006) Measurements of air-sea gas exchange at high speed winds in the Southern Ocean: Implications for global parameterizations. Geophysical Research Letters 33: 1-6.

Holt NW. (2006) Operational oceanography for the north west European Shelf Seas. In: Dahlin H, Flemming NC, Marchand P, et al. (eds) European Operational Oceanography: Present and Future (Proc. of 4th EuroGOOS Conference). EuroGOOS Office and European Commission, 281-285.

Hopkins FE, Nightingale PD and Liss PS. (2011) Effect of ocean acidification on the marine source of atmospherically active trace gases.: Oxford University Press.

Horsburgh K, de Vries H, Etala MP, et al. (2011) Guide to Storm Surge Forecasting. World Meteorological Organisation.

Høyer JL and Andersen OB. (2003) Improved description of sea level in the North Sea. Journal of Geophysical Research 108.

IAEA. (2014) Hot, sour and breathless - Oceans under stress. Available at: http://www.iaea.org/nael/relfiles/Ocean under Stress - English.pdf. Ivanova N, Johannessen OM, Toudal Perdersen L, et al. (2014) Retrieval of Arctic sea ice parameters by satellite passive microwave sensors : a comparison of eleven sea ice concentration algorithms. IEEE Transactions On Geoscience And Remote Sensing 52: 7233-7546.

Johannessen JA, Chapron B, Collard F, et al. (2008) Direct ocean surface velocity measurements from space: Improved quantitative interpretation of Envisat ASAR observations. Geophysical Research Letters 35: 1-6.

Kaleschke L, Tian-Kunze X, Maab N, et al. (2012) Sea ice thickness retrieval from SMOS brightness temperatures during the Arctic freeze-up period. Geophysical Research Letters 39. 
Kern S, Ozsoy-Cicek B, Willmes S, et al. (2011) An intercomparison between AMSR-E snowdepth and satellite C- and Ku-band radar backscatter data for Antarctic sea ice. Annals of Glaciology 52: 279-290.

Kettle $\mathrm{H}$ and Merchant CJ. (2005) Systematic errors in global air-sea $\mathrm{CO}_{2}$ flux caused by temporal averaging of sea-level pressure. Atmospheric Chemistry and Physics 5: 14591466.

Kettle H, Merchant CJ, Jeffery CD, et al. (2009) The impact of diurnal variability in sea surface temperature on the central Atlantic air-sea $\mathrm{CO}_{2}$ flux. Atmospheric Chemistry and Physics 9: 529-541.

Kim GE, Pradal M-A and Gnanadesikan A. (2015) Quantifying the biological impact of surface ocean light attenuation by coloured detrital matter in an ESM using a new optical parameterization. Biogeosciences 12.

Kock A and Bange HW. (2015) Counting the Ocean's greenhouse gase emissions.

Kozlov IE, Kudryavtsev VN, Johannessen JA, et al. (2012) Envisat ASAR imaging of coastal upwelling in the Baltic Sea: case study with modeling. Advances in Space Research 50: $1125-1137$.

Kudryavtsev VN, Akimov DD, Johannessen JA, et al. (2005) On radar imaging of current features: 1. model and comparison with observations. Journal of Geophysical Research 111.

Kudryavtsev VN, Kozlov IE, Chapron B, et al. (2014) Quad-polarization SAR features of ocean currents. Journal of Geophysical Research 119: 6046-6065.

Kudryavtsev VN, Myasoedov AG, Chapron B, et al. (2012) Imaging mesoscale upper ocean dynamics using synthetic aperture radar and optical data. Journal of Geophysical Research 117.

Kwok R. (2007) Near zero replenishment of the Arctic multiyear sea ice cover at the end of 2005 summer. Geophysical Research Letters 3.

Kwok R. (2010) Satellite remote sensing of sea-ice thickness and kinematics: a review. Journal of Glaciology 56: 1129-1140.

Kwok R, Cunningham GF, Wensnahan M, et al. (2009) Thinning and volume loss of the Arctic Ocean sea ice cover: 2003-2008. Journal of Geophysical Research 114.

Kwok R and Rothrock A. (2009) Decline in Arctic sea ice thickness from submarine and ICESat records : 1958-2008. Geophysical Research Letters 36. 
Kwok R, Spreen G and Pang S. (2013) Arctic sea ice circulation and drift speed: Decadal trends and ocean currents. Journal of Geophysical Research 118.

Lana A, Bell TG, Simo R, et al. (2011) An updated climatology of surface dimethlysulfide concentrations and emission fluxes in the global ocean. Global Biogeochemical Cycles 25.

Land PE, Shutler JD, Bell TG, et al. (2014) Exploiting satellite earth observation to quantify current global oceanic DMS flux and its future climate sensitivity. Journal of Geophysical Research.

Land PE, Shutler JD, Cowling RD, et al. (2013) Climate change impacts on air-sea fluxes of $\mathrm{CO}_{2}$ in three Arctic seas: as sensitivity study using Earth observation. Biogeosciences 10: $8109-8128$.

Land PE, Shutler JD, Findlay HS, et al. (2015) Salinity from space unlocks satellite-based assessment of ocean acidification. Environmental Science and Technology 49: 19871994.

Laxon S, Peacock N and Smith D. (2003) High interannual variability of sea ice thickness in the Arctic region. Nature 425: 947-950.

Laxon SW, Giles KA, Ridout AL, et al. (2013) CryoSat-2 estimates of Arctic sea ice thickness and volume. Geophysical Research Letters 40: 1-6.

Le Hénaff M, De Mey P and Marsaleix P. (2009) Assessment of observational networks with the Representer Matrix Spectra method-application to a 3D coastal model of the Bay of Biscay. Ocean Dynamics 59: 3-20.

Le Quere C, Peters GP, Andres RJ, et al. (2013) Global carbon budget 2013. Earth System Science Data Discussions 6: 689-760.

Le Traon P-Y and Dibarboure G. (1999) Mesoscale Mapping Capabilities of Multiple-Satellite Altimeter Missions. Journal of Atmospheric and Oceanic Technology 16: 1208-1223.

Le Traon P-Y, Nadal F and Ducet N. (1998) An improved mapping method of multisatellite altimeter data. Journal of Atmospheric and Oceanic Technology 15: 522-534.

Levinson JF, Khvorostovsky K, Ticconi F, et al. (2015) ESA ice sheet CCl: derivation of the optimal method for surface elevation change detection of the Greenland ice sheet round robin results. International Journal of Remote Sensing 36: 551-573.

Liss PS and Slater PG. (1974) Flux of gases across the air-sea interface. Nature 247. 
Madsen K, Høyer JL, West LJ, et al. (2014) Near Real Time altimetry measurements of the storm surge Bodil, Denmark - comparison with model and in-situ observations. Ocean Surface Topography Science Team Meeting.

Madsen KS, Høyer JL, Fu W, et al. (2015) Blending of satellite and tide gauge sea level observations and its assimilation in a storm surge model of the North Sea and Baltic Sea. Journal of Geophysical Research 120: 6405-6418.

Madsen KS, Høyer JL and Tscherning CC. (2007) Near - coastal satellite altimetry: Sea surface height variability in the North Sea-Baltic Sea area. Geophysical Research Letters 34.

Madsen SN. (1989) Estimating the Doppler centroid of SAR data. IEEE Transactions On Aerospace Electronic Systems AES25: 134-140.

Marshall J, Adcroft A, Hill C, et al. (1997) A finite - volume, incompressible Navier Stokes model for studies of the ocean on parallel computers. Journal of Geophysical Research 102: 5753-5766.

Maslanik JA, Stroeve J, Fowler C, et al. (2011) Distribution and trends in arctic sea ice age through spring 2011. Geophysical Research Letters 38.

McClain EP, Pichel WG and Walton CC. (1985) Comparative performance of AVHRR-based multichannel sea surface temperatures. Journal of Geophysical Research 90: 1158711601.

Meier WN, Fetterer F, Scott-Stewart J, et al. (2015) How do sea-ice concentrations from operational data compare with passive microwave estimates? Implications for improved model evaluations and forecasting. Annals of Glaciology 56: 332-340.

Mouche AA, Collard F, Chapron B, et al. (2012) On the Use of Doppler Shift for Sea Surface Wind Retrieval From SAR. IEEE Transactions On Geoscience And Remote Sensing 50: 2901-2909.

Mourre B, De Mey P, Ménard Y, et al. (2006) Relative performance of future altimeter systems and tide gauges in constraining a model of North Sea high-frequency barotropic dynamics. Ocean Dynamics 56: 473-486.

Muacho S, da Silva JCB, Brotas V, et al. (2013) Effect of internal waves on near-surface chlorophyll concentration and primary production in the Nazare Canyon (west of the Iberian Peninsula). Deep Sea Research Part I 81: 89-96. 
Murtugudde R, Beauchamp J, McClain CR, et al. (2002) Effects of penetrative radiation on the Upper Tropical Ocean Circulation. Journal of Climate 15: 470-486.

Nakamoto S, Prasanna Kumar S, Oberhuber JM, et al. (2000) Chlorophyll modulation of sea surface temperature in the Arabian Sea in a mixed-layer isopynical general circulation model. Geophysical Research Letters 27: 747-750.

Nightingale PD. (2009) Air-sea gas transfer. In: le Quere C and Saltzman ES (eds) Lower Atmosphere Surface Ocean Interactions. AGU Monograph, 69-98.

OhImann JC, Siegel DA and Cautier C. (1996) Ocean mixed layer radiant heating and solar penetration: A global analysis. Journal of Climate 9: 2265-2280.

Okkonen SR, Jacobs GA, Metzger EJ, et al. (2001) Mesoscale variability in the boundary currents of the Alaska Gyre. Continental Shelf Research 21: 1219-1236.

Passaro M, Cipollini P, Vignudelli S, et al. (2014) ALES: A multi-mission adaptive sub waveform retracker for coastal and open ocean altimetry. Remote Sensing of Environment 145: 173-189.

Peng SQ and Xie L. (2006) Effect of determining initial conditions by four-dimensional variational data assimilation on storm surge forecasting. Ocean Modelling 14: 1-18.

Potter RCH, Michelson-Jacob S, Fangohr S, et al. (2007) The prevalence of sea-surface slicks in the North Atlantic and marginal shelf seas.

Rabus B, Eineder M, Roth A, et al. (2003) The shuttle radar topography mission - a new class of digital elevation models acquired by spaceborne radar. Journal of Photogrammetry Remote Sensing 57: 241-262.

Rampal P, Weiss J and Marsan D. (2009) Positive trend in the mean speed and deformation rate of Arctic sea ice, 2019-2007. Journal of Geophysical Research 114.

Rees AP, Brown IJ, Clark DR, et al. (2011) The Lagrangian progression of nitrous oxide within filaments formed in the Mauritanian upwelling. Geophysical Research Letters 38.

Reul N, Tenerelli J, Chapron B, et al. (2012) SMOS satellite L-band radiometer: A new capability for ocean surface remote sensing in hurricanes. Journal of Geophysical Research-Oceans 117.

Riebesell U and Tortell PD. (2011) Ocean Acidification: Oxford University Press.

Robinson IS. (2010) Discovering the ocean from space: Springer. 
Romeiser R and Runge H. (2007) Theoretical evaluation of several possible along-track InSAR modes of TerraSAR-X for ocean current measurements. IEEE Transactions On Geoscience And Remote Sensing 45: 21-35.

Romeiser R, Suchandt S, Runge H, et al. (2010) First analysis of TerraSAR-X along-track InSAR-derived current fields. IEEE Transactions On Geoscience And Remote Sensing 48: 820-829.

Sabine CL, Feely RA, Gruber N, et al. (2004) The oceanic sink for anthropogenic $\mathrm{CO}_{2}$. Science 305: 367-371.

Salter ME, Upstill-Goddard RC, Nightingale P, et al. (2011) Impact of an artificial surfactant release on air-sea gas fluxes during Deep Ocean Gas Exchange Experiment II. Journal of Geophysical Research 116.

Santana-Casiano JM, Gonzalez-Davila M and Rueda MJ. (2007) The interannual variability of oceanic $\mathrm{CO} 2$ parameters in the northeast Atlantic subtropical gyre at the ESTOC site. Global Biogeochemical Cycles 21.

Sathyendranath S, Gouveia AD, Shetye SR, et al. (1991) Biological control of surface temperature in the Arabian Sea. Nature 349: 54-56.

Sathyendranath S and Platt T. (1988) The spectral irradiance field at the surface and in the interior of the ocean: A model for applications in oceanography and remote sensing. Journal of Geophysical Research 93: 9270-9280.

Sathyendranath S and Platt T. (2000) Mixed-layer dynamics and primary production in the Arabian Sea. In: Hanson RB, Ducklow HW and Field JG (eds) The changing ocean carbon cycle: A midterm synthesis of the Joint Global Ocean Flux Study. Cambridge Univ. Press, 285-299.

Sathyendranath S and Platt T. (2007) Spectral effects in bio-optical control on the ocean system. Oceanologia 49: 5-39.

Shell KM, Frouin R, Nakamoto S, et al. (2003) Atmospheric response to solar radiation absorbed by phytoplankton. Journal of Geophysical Research.

Shuchman R. (1979) The feasibility of measurement of ocean current detection using SAR data. 13th Int. Symp. Remote Sens. of Environment. Miama, US., 93-103.

Shutler JD, Land PE, Brown CW, et al. (2013) Coccolithophore surface distributions in the North Atlantic and their modulation of the air-sea flux of $\mathrm{CO}_{2}$ from 10 years of Earth observation data. Biogeosciences 10: 2699-2709. 
Siegel DA, Ohlmann JC, Washburn L, et al. (1995) Solar radiation, phytoplankton pigments and the radiant heating of the equatorial Pacific warm pool. Journal of Geophysical Research 100: 4885-4891.

Sørensen JVT and Madsen H. (2004) Efficient Kalman filter techniques for the assimilation of tide gauge data in three - dimensional modeling of the North Sea and Baltic Sea system. Journal of Geophysical Research 109.

Stammer D, Ray RD, Andersen OB, et al. (2014) Accuracy assessment of global barotropic ocean tide models. Reviews in Geophysics 52: 243-282.

Stewart RH. (2012) Introduction to Physical Oceanography, online: OceanWorld.

Stirling I and Derocher AE. (2012) Effects of climate warming on polar bears: a review of the evidence. Global Change Biology 18: 2694-2706.

Stocker TF, Qin D, Plattner GK, et al. (2013) Climate change 2013: The physical science basis. .

Stroeve JC, Serreze MC, Holland MM, et al. (2012) The Arctic's rapidly shrinking sea ice cover: a research synthesis. Climate Change 110: 1005-1027.

Swail V, Lee B, Soares A, et al. (2010) Storm surge. In: Hall J, Harrison DE and Stammer D (eds) OceanObs 2009: Sustained Ocean Observations and Information for Society.

Swan AM and Long DG. (2012) Multiyear Arctic sea ice classification using QuikSCAT. IEEE Transactions On Geoscience And Remote Sensing 50: 3317-3326.

Takahashi T, Sutherland SC, Wanninkhof R, et al. (2009) Climatological mean and decadal change in surface ocean $p \mathrm{CO}_{2}$ and net sea-air $\mathrm{CO}_{2}$ flux over the global oceans. Deep Sea Research // 56: 554-577.

Tandeo P, Chapron B, Ba S, et al. (2014) Segmentation of Mesoscale Ocean Surface Dynamics Using Satellite SST and SSH Observations. leee Transactions. IEEE Transactions On Geoscience And Remote Sensing 52: 4227-4235.

Tilling RL, Ridout A, Shepherd A, et al. (2015) Increased Arctic sea ice volume after anomalously low melting in 2013. Nature Geoscience 8: 643-646.

Torres R, Snoeij P, Geudtner D, et al. (2012) GMES Sentinel-1 Mission. Remote Sensing of Environment 120: 9-24.

Tournadre J, Chapron B, Reul N, et al. (2006) A satellite altimeter model for ocean slick detection. Journal of Geophysical Research 111. 
Vancoppenolle M, Fichefet T and Goosse H. (2009) Simulating the mass balance and salinity of arctic and antarctic sea ice. 2. Importance of sea ice salinity variations. Ocean Modelling 27: 54-69.

Verlaan M, Zijderveld A, de Vries $\mathrm{H}$, et al. (2005) Operational storm surge forecasting in the Netherlands: developments in the last decade. Philosophical Transactions of the Royal Society A 363: 1441-1453.

Vignudelli S, Kostianoy AG, Cipollini P, et al. (2011) Coastal altimetry: Springer.

Vihma T. (2014) Effects of Arctic sea ice decline on weather and climate : a review. Surveys in Geophysics 35: 1175-1214.

Wadhams. (2000) Ice in the Ocean: CRC Press.

Wanninkhof R, Asher WE, Ho DT, et al. (2009) Advances in quantifying air-sea gas exchange and environmental forcing. Annual Reviews of Marine Science 1: 213-244.

Watson AJ and Orr JC. (2003) Carbon dioxide fluxes in the global ocean: Berlin: Springer.

Wentz FJ. (1997) A Well-calibrated Ocean Algorithm for SSM/I. Journal of Geophysical Research 102: 8703-8718.

Whitman WG. (1923) The two-film theory of gas absorption. Chem. Metall. Engng 29: 146-148. WHO. (2014) Nutrition: Global and regional food consumption patterns and trends. Available at: http://www.who.int/nutrition/topics/3_foodconsumption/en/index5.html. Woolf DK and Gommenginger C. (2008) Radar altimetry: Introduction and application to air-sea interaction. In: Barale V and Gade M (eds) Remote Sensing of the European Seas. Springer Verlag, 283-294.

Woolf DK and Ufermann S. (2005) Can dual-frequency altimetry be used to identify surface slicks ? EARSel 2nd Workshop on Remote Sensing of the Coastal Zone. Portugal.

Wu Y, Tang C, Sathyendranath S, et al. (2007) The impact of bio-optical heating on the properties of the upper ocean: a sensitivity study using a 3-D circulation model for the Labrador Sea. Deep Sea Research Part II 54: 2630-2642.

Yang H, Choi J-K, Park Y-J, et al. (2014) Application of the Geostationary Ocean Color Image $(\mathrm{GOCl})$ to estimates of ocean surface currents. Journal of Geophysical Research 119: 3988-4000.

Young IR, Zieger S and Babanin AV. (2011) Global Trends in Wind Speed and Wave Height. Science 332: 451-455. 
Zakhvatkina NY, Alexandrov VY, Johannessen OM, et al. (2013) Classification of sea ice types in ENVISAT SAR images. IEEE Transactions On Geoscience And Remote Sensing 51: 2587-2600.

Zhai L, Tang C, Platt T, et al. (2011) Ocean response to attenuation of visible light by phytoplankton in the Gulf of St. Lawrence. Journal of Marine Systems 88: 285-297.

Zieger S, Vinoth J and Young IR. (2009) Joint Calibration of Multiplatform Altimeter Measurements of Wind Speed and Wave Height over the Past 20 Years. Journal of Technology 26: 2549-2564. 
Infra-red Optical Passive Microwave Scatterometer SAR Altimeter Other

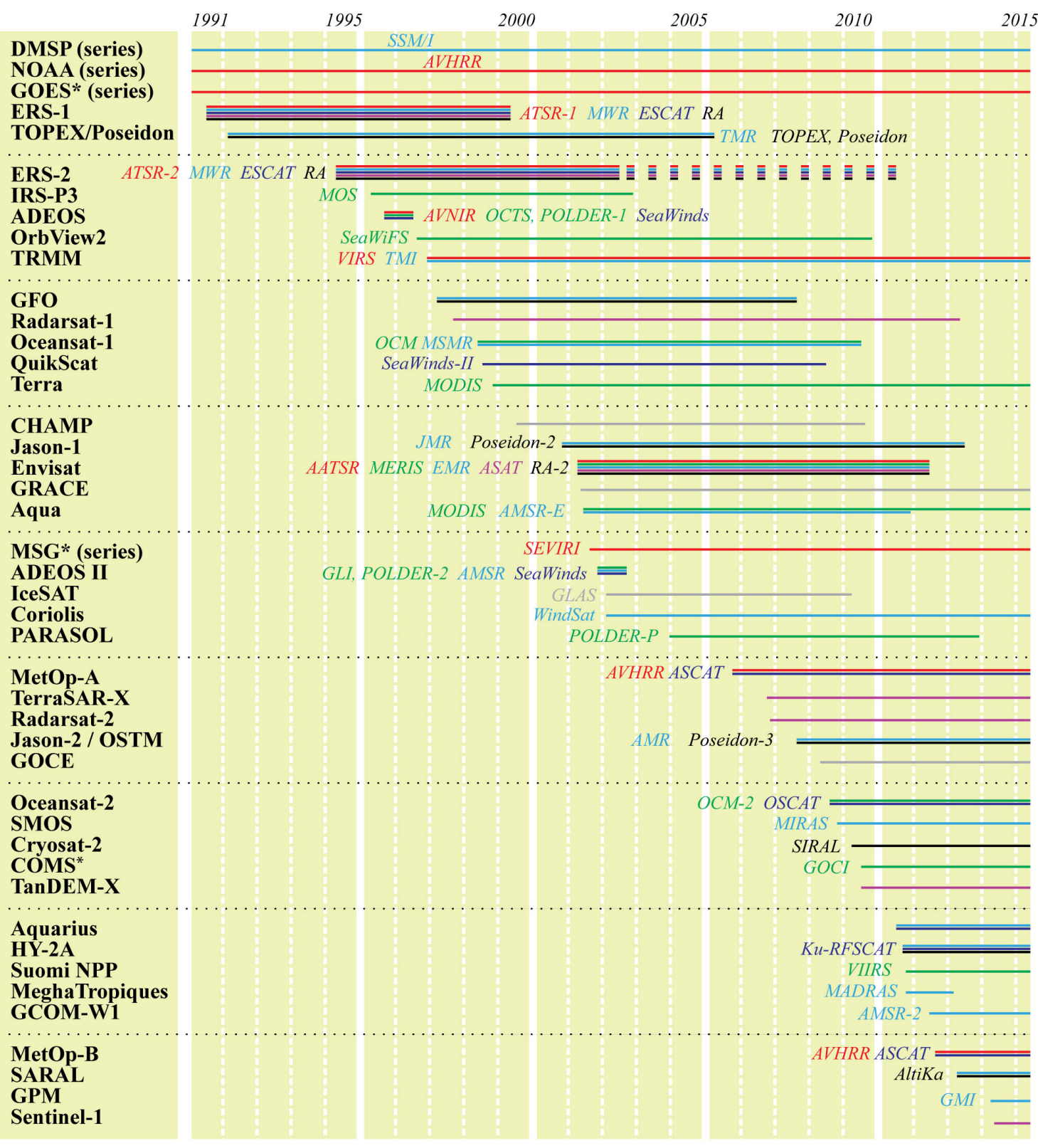

Figure 1: Timelines for all the key ocean remote-sensing instruments used to studying and monitoring physical oceanography, with names given when different from the spacecraft. The passive microwave sensors do not all share the same frequency channels, as these depend upon the parameters of interest, and those co-manifested with an altimeter are nadir-viewing only rather than providing swath coverage. All the satellites are in low Earth orbits, except for those asterisked, which are in geostationary orbits. GLAS was a laser altimeter, whilst CHAMP, GRACE and GOCE measure the gravitational field. ERS-2 lost its last on-board tape recorder in June 2003, so subsequent coverage was limited to regions with direct reception. Source: constructed by co-author G. Quartly using Adobe Illustrator. 


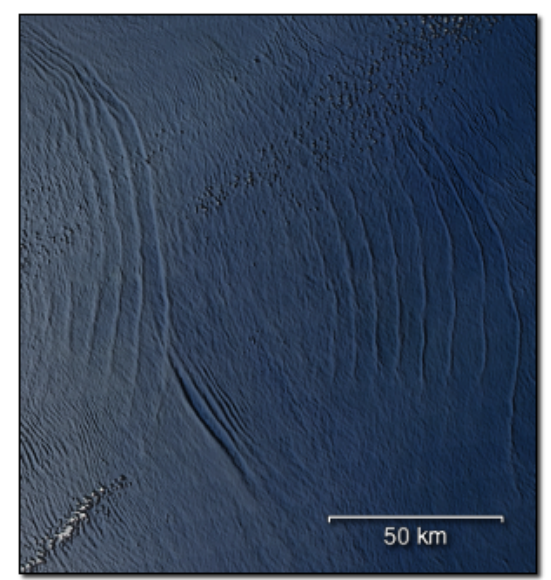

a)

Figure 2: Example satellite remote sensing data of physical oceanography a) - 5 March 2014 Aqua-MODIS data showing the surface signatures of internal waves in the Andaman Sea (source: NASA Ocean Colour Biology Group); b) Surface currents inferred from visible spectrum ocean colour data using maximum cross correlation. Source: European Space Agency GlobCurrent project and Dr Weidong Xu.

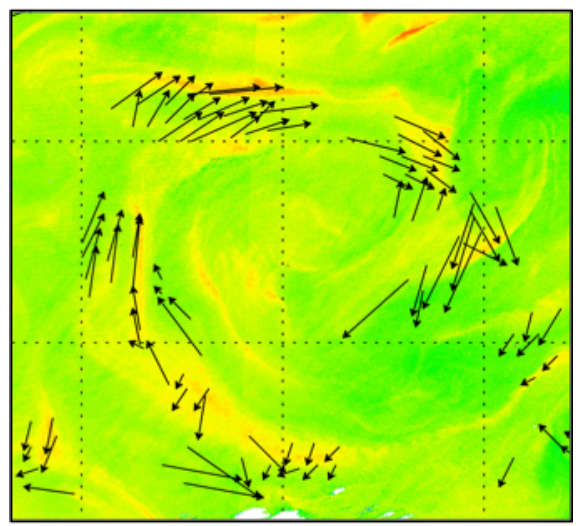

b) 

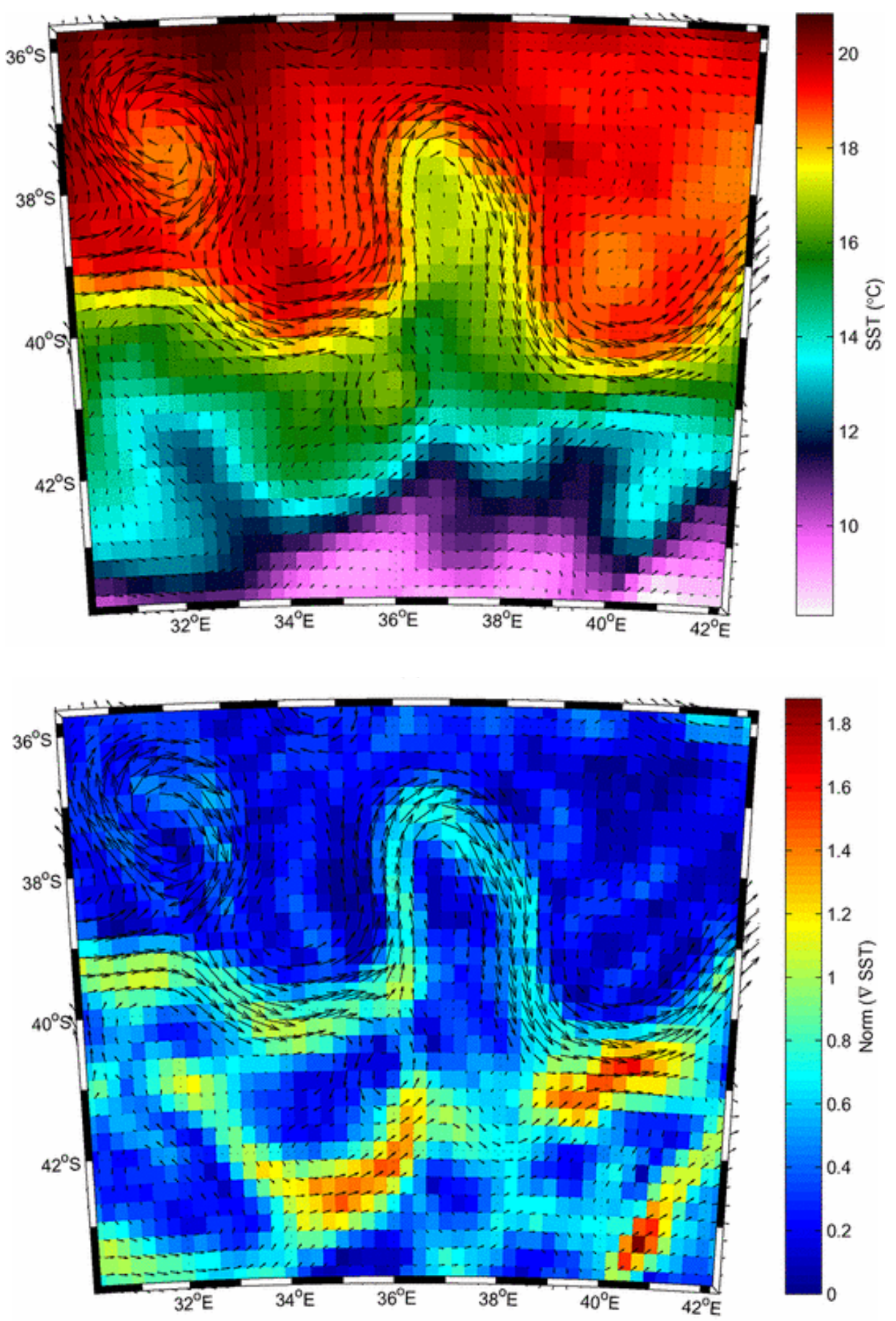

Figure 3 The Agulhas return current as seen from altimeter and passive microwave data on January 1, 2004. Top: Surface currents derived from altimeter sea surface heights (SSHs) and overlaid on the microwave sea surface temperature data. Bottom: the associated temperature gradient differences (labelled norm) with the same surface currents overlaid. Source: Reproduced with the permission of the authors from figure 1 of (Tandeo et al., 2014). 


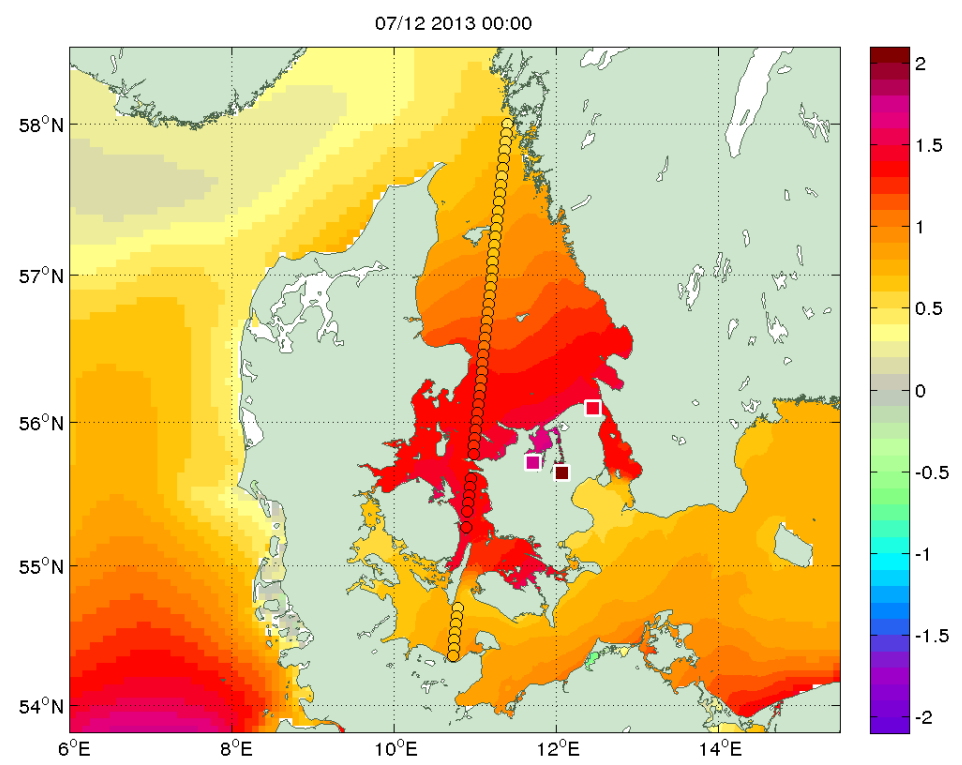

Figure 4 Example of satellite altimetry verification of model performance. Cryosat-2 observations (filled circles) and tide gauge observations (filled squares) are overlaid the Danish Meteorological Institute (DMI) storm surge model field. The surge occurred during the Bodil storm 6-7 December 2013 and resulted in a 1000 years event in Roskilde, Denmark. Source: Generated by co-author J. Høyer. 


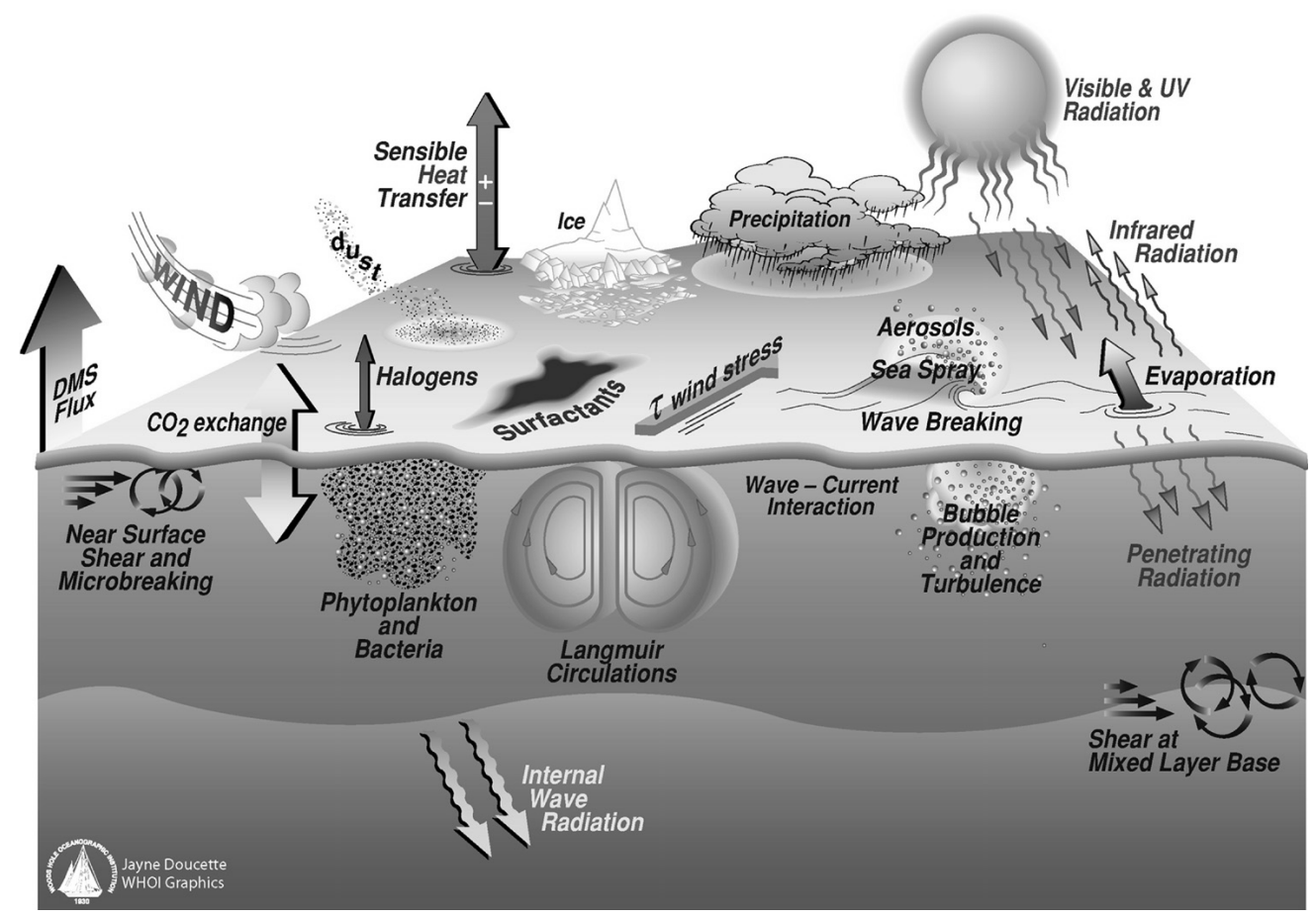

Figure 5 The air-sea flux of gases and the various processes that are believed to control these fluxes. Original image by Jayne Doucette, Woods Hole Oceanographic Institution, and Wade McGillis, Columbia University. 


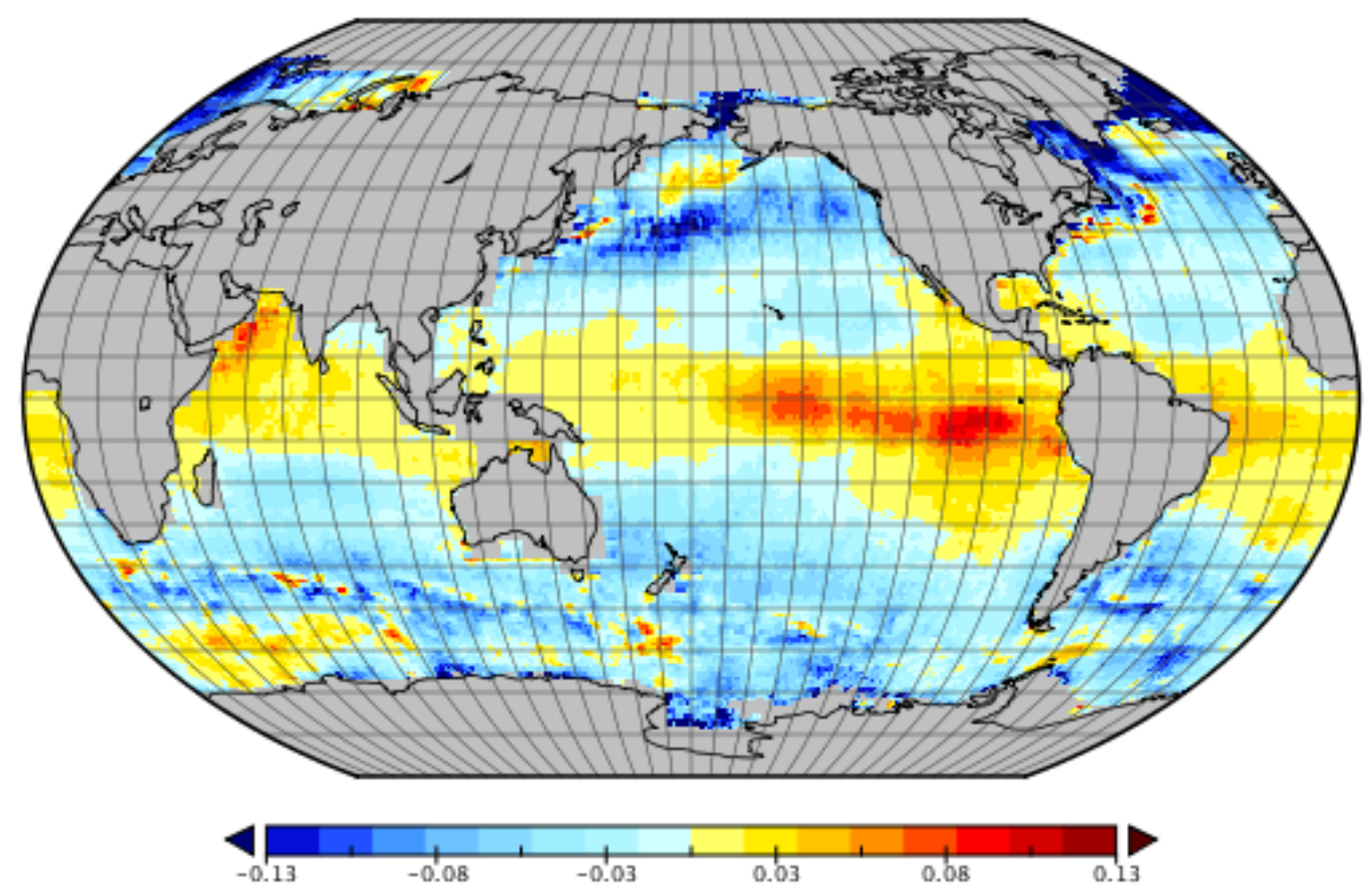

a)

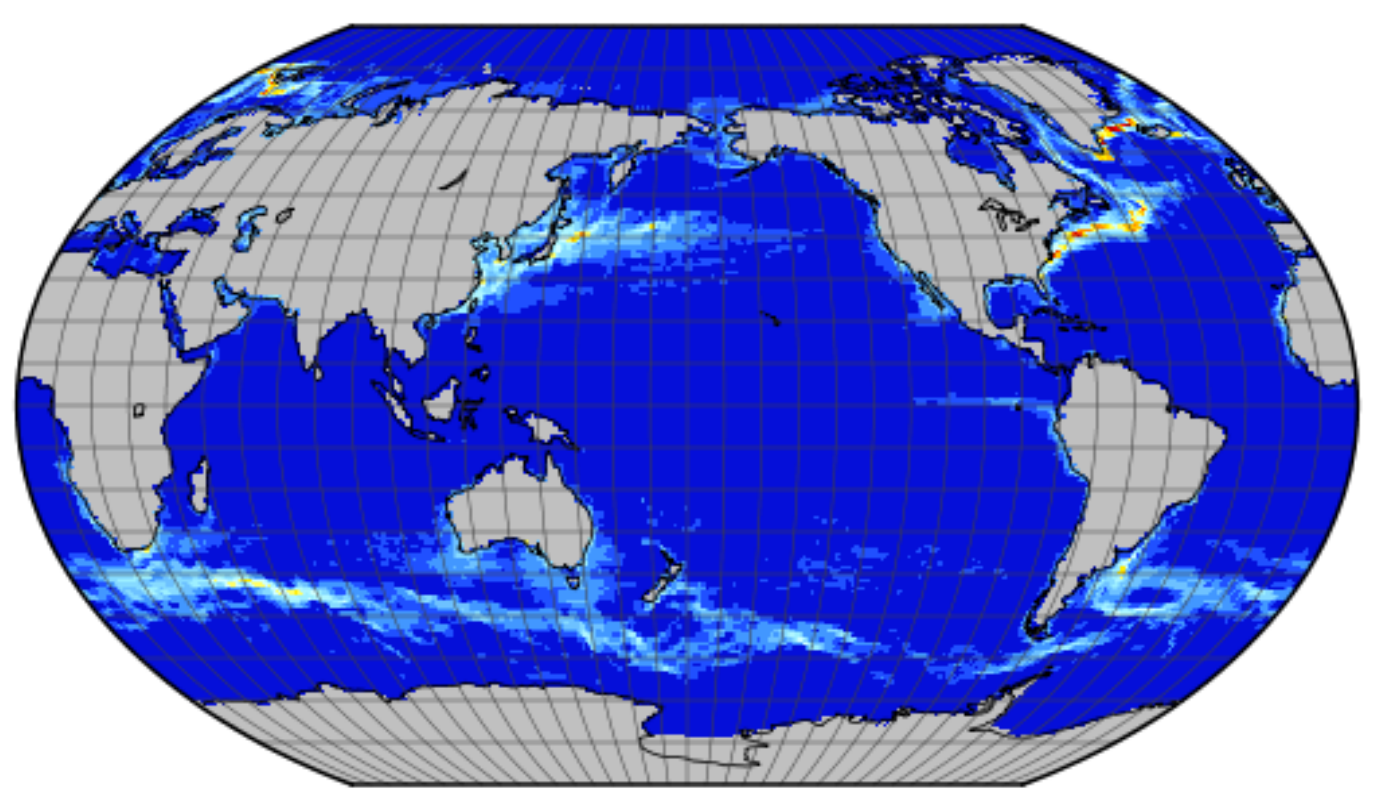

b)

Figure 6 Global atmosphere-ocean $\mathrm{CO}_{2}$ gas fluxes derived from satellite remote-sensing, model and in situ data by the ESA OceanFlux Greenhouses project. a) global annually averaged mean air-sea $\mathrm{CO}_{2}$ flux in grams of carbon per metre squared per day $\left(\mathrm{gC} \mathrm{m}^{-2}\right.$ day $\left.^{-1}\right)$. b) The position of persistent oceanic currents as derived satellite remote-sensing used to help interpret the global gas fluxes in a). Colours are only provided to indicate the strength and position of the surface features. Light blue suggests a stronger surface current, whereas dark blue suggests no current. Images courtesy of the European Space Agency. 